\title{
Neolithic pottery and the biomolecular archaeology of lipids
}

\author{
Mihael Budja \\ University of Ljubljana, Faculty of Arts, Department of Archaeology, SI \\ miha.budja@ff.uni-lj.si
}

\begin{abstract}
In this paper, we present archaeological and biochemical approaches to organic food residues, the lipids that are well preserved in ceramic matrices on prehistoric vessels. The 'archaeological biomarker revolution' concept is discussed in relation to pottery use, animal exploitation and the evolution of dietary practices in prehistory.
\end{abstract}

IZVLEČEK - V prispevku predstavljamo arheološke in biokemijske raziskave organskih ostankov hrane, lipidov ohranjenih $v$ stenah keramičnih prazgodovinskih posod. Koncept 'revolucije arheoloških biomerkerjev' analiziramo v povezavi z uporabo keramičnih posod, izrabo živalskih virov in razvojem mlečnega gospodarstva v prazgodovini.

KEY WORDS - Neolithic; pottery; organic residues; lipids; biomarker revolution; fatty acids; stable isotopes

\section{Introduction}

Organic residues on pottery have become broadly recognised as remnants of the original vessel contents or the accumulated remnants of its multiple uses since David Braun (1983) introduced the perception of 'pots as tools', in which vessels are seen as containers designed to play a set of utilitarian roles. Elizabeth F. Henrickson (1990) distinguishes between the terms 'use' and 'function'. While use refers to the specific utilitarian tasks of vessels, the function is defined as a broad term for the agency encompassing the way in which a vessel and pottery assemblage fit into the social, economic, and ritual contexts of a cultural system, and the roles pottery is called on to play within them. In parallel, the determination of intended use was correlated to the performance characteristics of pottery manufacture, i.e. fabric, shape, and firing (Rice 1987), accessibility, stability and transportability (Skibo 2013), and with shifts in diet and food in different archaeological and ethno-archaeological contexts (Henrickson, McDonald 1983; Schiffer, Skibo 1987; Kimple et al. 2004; Skibo 2013).
The term organic residue covers a variety of amorphous organic remains, lipids that lack the clearly discernible morphological features that characterise other biological materials. Their identification relies on chemical and biochemical analyses. Visible and absorbed organic residues are usually regarded as remnants of the original vessel contents, the accumulated remnants of multiple uses, and one or more cooking episodes of burning of food due to overheating of vessels. These residues are "typically chemically complex (commonly comprising hundreds of compounds of different classes, such as fatty acids and their derivatives, terpenes or polymers) and degraded (due to anthropic and natural degradation) mixtures of unknown organic compounds at low concentration" (Salque 2012.130).

Visible residues can be observed as charred deposits encrusted (food-crust) on the interior and exterior of vessels (Fig. 1). Those on the outer walls may derive from soot deposited during the heating of the vessel over a fire. Resinous substances could have 
been applied during the manufacturing processes to reduce the permeability of porous fabrics. Residues on interior surfaces are highly charred and amorphous, but may provide direct and indirect evidence of their use. They are of animal or plant origin and may derive from animal fats, dairy products, beeswax, fermented beverages, resins, and tars ( $R e$ gert 2011.178; see also Colombini, Modugno 2009) (Fig. 2). It has been suggested that surface residues 'are probably the result of the last, or one of the last, phases of vessel use', which increases the likelihood of identification of the original vessel content $\mathrm{OOu}$ demans, Boon 1993.222), and that they contain 'a more intact' lipids profile because those extracted from the ceramic matrix have been thermally degraded by repetitive heating of the vessel wall ( $\mathrm{Ou}$ demans, Boon 2007). Kenneth Peters, Clifford Walters and Michael Moldovan (2005.342) suggested on the contrary that charred food remains on the surfaces of cooking pots 'can be identified by visual inspection but provide less chemical information on their origins'. It has also been suggested that surface residues have been thermally altered, degraded and contaminated before and after deposition (Regert et al. 1998; Craig et al. 2007.137).

However, the combined archaeometrical pottery analysis, and botanical and chemical analyses of charred residues performed on Early Neolithic Swifterbant pottery show a correlation between pottery technology and function on the one hand, and between micro-fragments of partially charred foods prepared in the vessel and lipids, both identified in surface residue on the other. Thus micro-fragments of leaf tissue, roots and tubers and emmer chaff epidermis (Triticum dicoccum), correlate with the remains of fish scales and terrestrial animal bones, and with free fatty acids, acylglycerides, sterols and acyllipids (Raemaekers et al. 2013; Oudemans, Kubiak-Martens 2012).

Lipids were successfully recovered from charred surface deposits on Incipient $\mathbf{J} \overline{0}-$ mon pottery (c. 15000 to 11800 calBP) on Hokkaido, Honshu and Kyushu Islands. The lipids profiles in charred surface deposits show organic compounds consisting of saturated fatty acids derived from processing freshwater and marine organisms (Craig et al. 2013).

In North America, the regional histories of maize utilisation have been intensi-

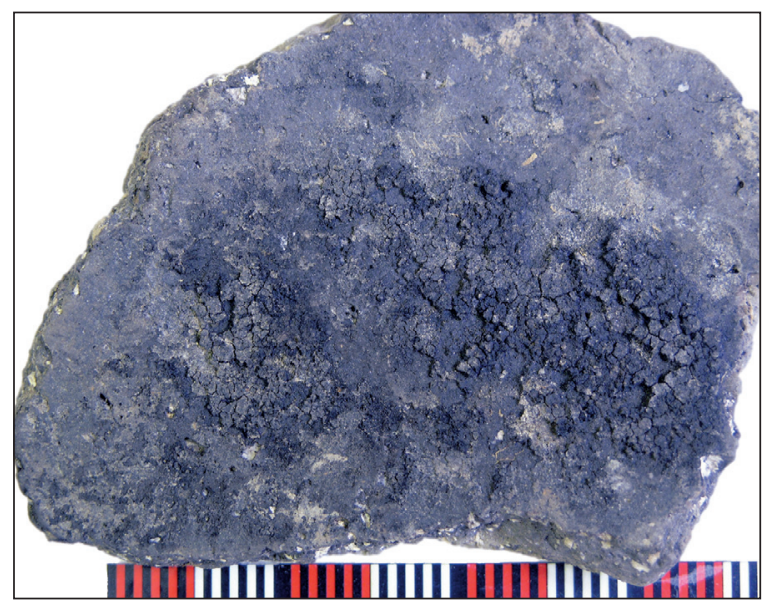

Fig. 1. A surface residue on the Neolithic pottery at Maharski prekop site (photo: M. Budja).

vely studied using bulk values of stable carbon isotopes $\delta 13 \mathrm{C}$, maize phytoliths and starches derived from charred cooking residues. The basic assumptions were that maize was the only $\mathrm{C}_{4}$ resource cooked in a pot along with $\mathrm{C}_{3}$ legumes and other plants, and that there was a linear relationship between the proportion of maize cooked in a pot relative to legumes and bulk $\delta^{13} \mathrm{C}$ values on residues. The presence of $\mathrm{C}_{4}$ maize in a mixture with $\mathrm{C}_{3}$ legumes would result in higher bulk $\delta^{13} \mathrm{C}$ values on residues. The $-24 \%$ o $\delta^{13} \mathrm{C}$ bulk value was recognised as a proxy signature of maize presence (Hastrof, DeNiro 1985; Morton, Schwarcz 2004). The analytical work focused on isotope ratio mass spectrometry and was first limited to 'bulk' carbon $\left(\delta^{13} \mathrm{C}\right)$ and nitrogen $\left(\delta^{15} \mathrm{~N}\right)$ isotope compositions of carbonised food remains (DeNiro 1987). It was recognised recently as a 'very blunt analytical tool' unsuitable for

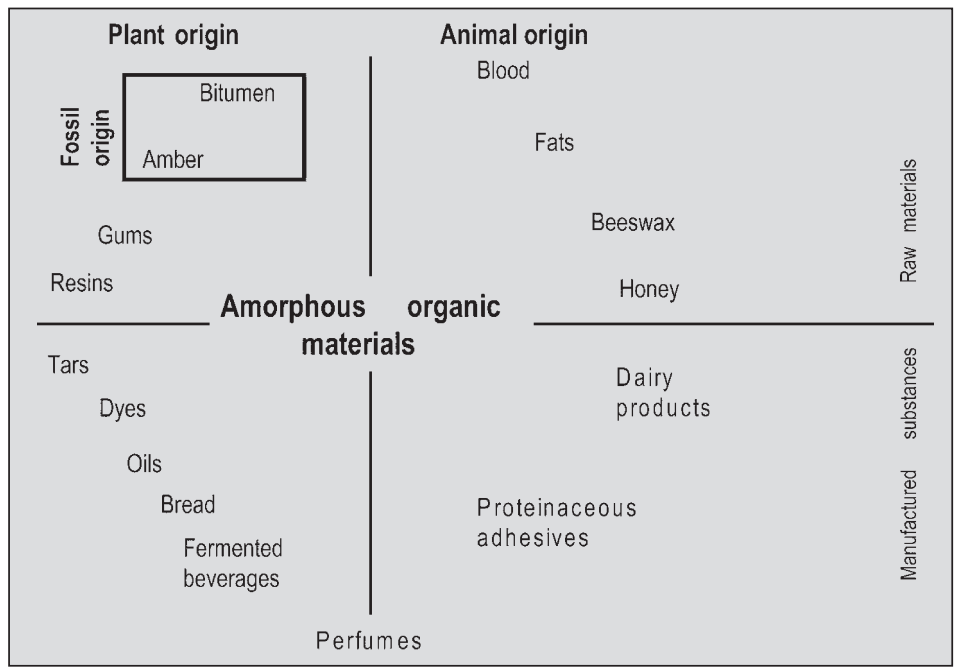

Fig. 2. Natural substances that may have been preserved as amorphous organic residues on prehistoric vessels (reprinted from Regert 2011.Fig. 1, copyright 2010 by Wiley Periodicals, Inc.). 
distinguishing complex mixtures of biomolecules derived from a number of poorly defined origins of food constituents (Craig 2007.137). The experiments suggest that maize cannot be identified from bulk $\delta^{13} \mathrm{C}$ values even when it contributed substantially to the food mix, and that different carbon mobilisation from $\mathrm{C}_{3}$ and $\mathrm{C}_{4}$ resources over time is an important variable in residue formation and in determining bulk values (Hart et al. 2007; 2009; 2012). They even show that the decomposition of lipids was rapid, thus making maize lipids in bulk values unidentifiable. Their identification can be performed with compound-specific stable isotope analysis only (Reber, Evershed 2004).

Invisible residues are absorbed by porous ceramic fabric and usually better preserved than surface deposits, because the ceramic microstructure protects them from microbial degradation. They are very common, 'probably being present in $80 \%$ or more' of all archaeological pottery assemblages (Brown, Brown 2011.194). It is believed that absorbed residues include compounds from the entire use of vessels, as the lipids absorbed in archaeological pottery represent an integrated signature, reflecting a number of occasions of use rather than simply the last or even later uses of a vessel (Evershed 2008a.35).

During boiling or roasting of food, organic compounds like lipids, proteins, carbohydrates, and other biopolymers are liberated or mobilised from foodstuffs. Different processes preserve these compounds in absorbed residues, but it seems they are hydrophilic enough to dissolve in cooking liquid and thus be absorbed into pot walls, but also hydrophobic enough not to wash out during deposition. Lipids represent the largest and most enduring portion of these residues because of their hydrophobicity and greater resistance to structural modification compared to proteins and carbohydrates. However, even the lipid components deposited in ceramic vessels are preserved in low concentrations and highly degraded. Degradation and loss of residue begin over the course of cooking and continue after discard and deposition through pyrolysis, bacterial action and autoxi-

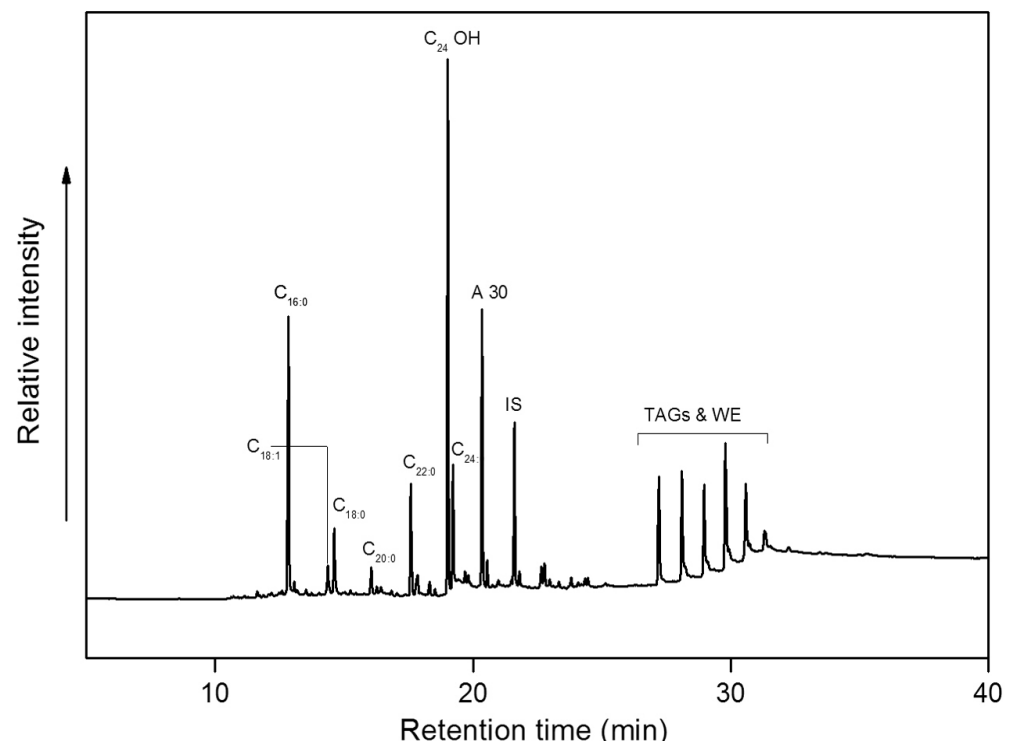

Fig. 4. Partial high temperature gas chromatogram of trimethylsilylated total lipid extracts that is characteristic of ruminant dairy fats and degraded beeswax from the Maharski prekop pottery sample MP59 (Ogrinc et al. 2015 in prep.). dation. The duration of burial is probably less important for residue survival than the prevailing conditions within the burial environment. Experimental studies have shown the variability of lipid preservation with burial environments and that anoxic conditions favour organic residue preservation. They indicate that only a small fraction of lipid originally absorbed survives burial. It was suggested that $99 \%$ of the extractable lipid missing from food residues is lost principally through microbial action. The surviving lipids - the fraction of molecules that survives is presumed to be due to their protection in molecular-sized pores within the clay fabric microstructure or strong absorption into the clay surface (Evershed 2008a.28-29). The latter was also suggested to be significant in the survival of protein residues as well (Craig, Collins 2002). 
Analyses show that many cooking vessels displayed greater lipid concentrations in the upper parts of vessels and much lower or negligible accumulation in their bases (Fig. 3). A notable difference appears in the absolute concentration of lipid deposited in the vessel wall in mixed residues like meat and vegetables. Meat dominates over vegetables, showing higher concentrations of triacylglycerols than of leaf wax. This difference is most strongly influenced by the lipid richness of the source foodstuff and the degradation resistance of components from different sources (Evershed 2008a.31-35). Since the 1990s the determination of nature and origin of lipids, which mostly derived from degraded animal fats based on the distribution of fatty acids, sterols, monoacylglycerols, diacylglycerols, and triacylglycerols, was a great challenge because they reflect a range of complex transformations and mixtures and have undergone a series of alteration processes. The introduction of biomarker concept and HTGC-MS combined with carbon isotopic analysis of individual fatty acid by GC-C-IRMS analytical tools and soft ionization techniques have offered the possibility to differentiate ruminant and nonruminant fats, and to detect dairy products (e.g., goat and cow milk) in Neolithic ceramic vessels.

\section{Lipids}

Lipids are a broad group of organic macromolecules produced by living organisms, which include fats, oils, waxes, steroids, and various resins. The main biological functions of lipids include storing energy and acting as structural components of cell membranes. Plants, animals, and other living organisms use fats and oils as stored forms of energy. Fats and oils are stored in the adipose cells of animals, forming adipose tissue, and in the seeds of plants. Within a wide variety of organic compounds which are categorised as lipids, the fatty (carboxylic) acids (FAs), triacylglycerols (TAGs), steroids, waxes and terpenes are recognised as useful in the analysis of prehistoric food residues. FAs rarely occur as free, isolated molecules in nature, but they most often occur as parts of TAGs, in which three fatty acids are bonded to a single glycerol molecule through ester linkages.

Lipids are relatively resistant to degradation by chemical and microbial processes and can survive with little structural change for long periods. They are recognised as 'simple' and 'complex'. The first consist of TAGs, and their derivatives derived from hydrolysis, such as diacylglycerols (DAGs) and monoacylgly-

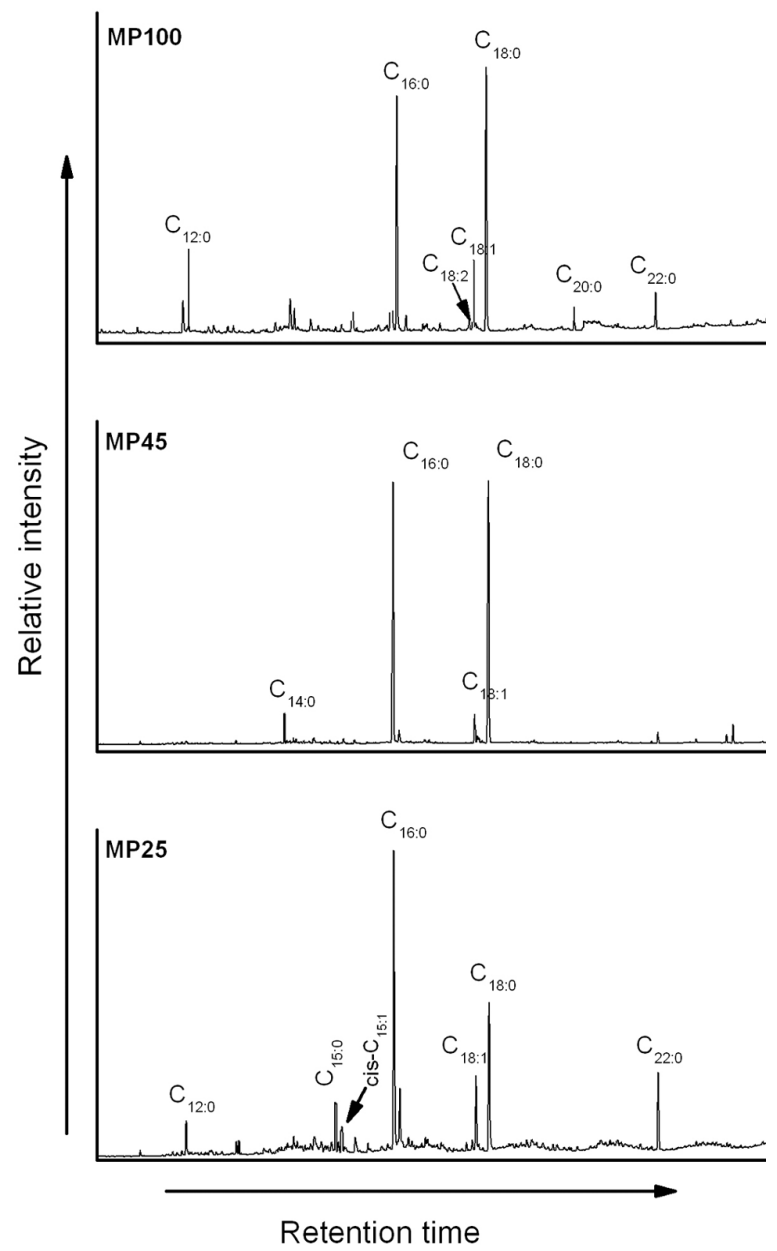

Fig. 5. The representative GC-MS total ion chromatograms of the FAs methylesters (FAMEs) with different $C_{16: 0}$ and $C_{18: 0}$ abundance extracted from the Maharski prekop pottery samples (from Ogrinc et al. 2012.Fig. 3).

cerols (MAGs), free fatty acids (FAs), as well as other sterol-containing metabolites such as sterols (cholesterol), esters (waxes) and lipoproteins. The latter consist of phospholipids and glycolipids. TAGs are the main storage form of fats within the body, where their main function is to store energy. Nearly all fats and oils of animal and plant origin consist almost exclusively of TAGs.

FAs rarely occur as free molecules in nature, but are usually found as components of lipid molecules like fats and oil, and phospholipids. While FAs derive from dietary sources or produced by the metabolic breakdown of stored fats, phospholipids serve as major components of cell membranes and have an essential role in photosynthesis (Pollard et al. 2007; Colombini, Modugno 2009).

Fatty acid structure is one of the most fundamental categories of lipids, and is commonly used as a build- 
Fig. 6. Partial gas chromatogram of the total lipid extract (trimethylsilylated) of an Early Bronze Age cooking vessel, showing the presence of long-chain ketones formed by thermal free radical condensation of the FAs present in the same extract. Peak identities are $C_{16: 0}$ and $C_{18: 0,}$ which indicate saturated fatty acids (palmitic and stearic), and $C_{18: 1}$ (oleic) that indicates $a$ monounsaturated fatty acid. $K$, the long mid-chain ketones with the preceding number corresponds to

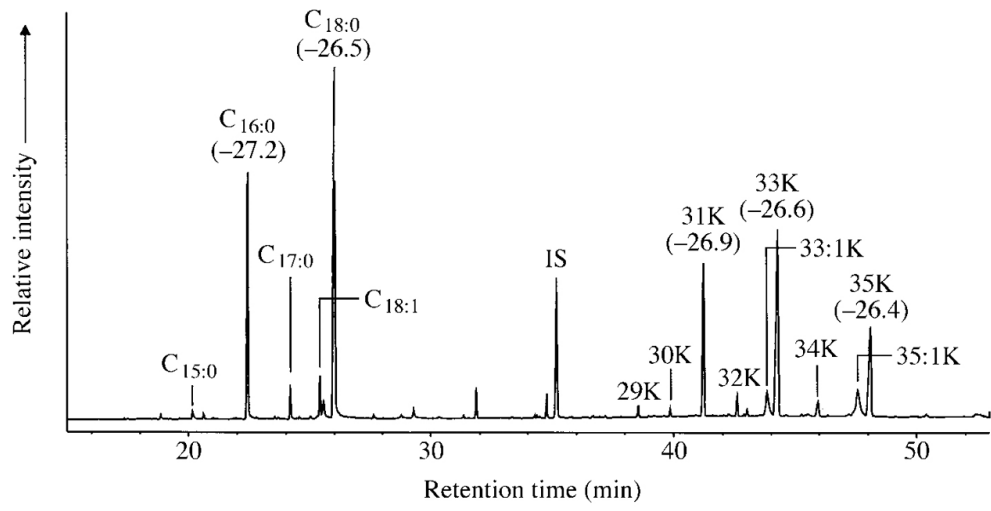
the number of carbon atoms in each component. IS is internal standard (5a-cholestane). Values in parentheses refer to the $13 \mathrm{C}$ values of the individual compounds determined by GC/C-IRMS (reprinted from Evershed et al. 1999.Fig. 2).

ing-block of more structurally complex lipids. FA is a carboxylic acid with a long aliphatic chain. The main FAs found in plant and animal foods have a chain of an even number of carbon atoms ranging from 4 to 36, which is either saturated or unsaturated. Unsaturated FAs have one or more double bonds between carbon atoms. Saturated FAs usually have between 12 and 24 carbon atoms and have no double bonds. When they are not attached to other molecules, they are known as 'free' fatty acids produced from the breakdown of TAGs. The more abundant saturated (unbonded) FAs are the palmitic $\left(\mathrm{C}_{16: 0}\right)$, and stearic $\left(\mathrm{C}_{18: 0}\right)$ acids, followed by lauric $\left(\mathrm{C}_{12: 0}\right)$, myristic $\left(\mathrm{C}_{14: 0}\right)$; the unsaturated (bonded) acids are palmitoleic $\left(\mathrm{C}_{16: 1}\right)$, oleic $\left(\mathrm{C}_{18: 1}\right)$, linoleic $\left(\mathrm{C}_{18: 2}\right)$, and linolenic $\left(\mathrm{C}_{18: 3}\right)$. These FA distributions are typical of degraded fats, and have a strong biological signature. While unsaturated FAs are more abundant in food of vegetable origin, small quantities of branched-chain fatty acids are present in many plants and animals (especially ruminants and fish), and in much larger concentrations in many bacteria (Spangenber et al. 2006; Eerkens 2007).

\section{'The archaeological biomarker revolution'1}

Since all the organic materials processed in vessels are of biological origin, they will be complex mixtures. The complexity increases through human activities (e.g., mixing biological materials in food pre- paration), followed then by the compositional alteration of residual matrices due to continuous vessel heating (pyrolysis), and decay during burial (diagenesis). Richard Evershed (1993) proposed using biomarkers as identifiers of the origin of food components in complex molecular mixtures in prehistoric vessels. The conceptualisation was embedded in the 'biomolecular archaeology of lipids', which concerns the recognition and origin of "the properties of the individual compounds or mixtures of compounds" in organic residues in pottery. He suggested that it is possible to identify the origin of lipids in a ceramic matrix by "matching the structures of individual compounds, or the relative proportions of the components of a mixture of compounds, to those found in contemporary plant and animal natural products likely to have been exploited in antiquity" (Evershed 1993.79).

His identification of 'lipid biomarkers' in organic residues in pottery is related to recognitions of: (i) 'sterols and sterol derivatives' in which cholesterol is the most abundant animal sterol, while campesterol and sitosterol are the two major plant sterols; (ii) 'fatty acids and acyl lipids' in which FAs, DAGs, MAGs and TAGs are detected as being associated with animal fats, dairy products, vegetable oils and fish/marine oils; and (iii) 'long chain alkyl (acyclic)' compounds that relate to beeswax and plant waxes. The main chemical characteristics that constitute

1 Evershed (2008b.898) introduced a syntagm recently, relating it to 'archaeological biomarker concept' that relies upon matching the structures or distributions, 'chemical fingerprints', to the compounds and mixtures known to exist in extant organisms likely to have been exploited in the past. Sometimes the structure of a single component is sufficient to define the origin of a constituent of an organic residue. Betulin is thus marking the Birck bark, Boswellic acid the Frankincense, and Moronic acid the Pistacia spp. Beeswax is further example. It can be readily recognized because of the characteristic mixture of aliphatic components that it contains. However, the fundamental aspects of the biomarker approach is ability to recognize an original constituent or source, of an organic residue based upon altered structures surviving in the residues. It requires knowledge of the chemical and biochemical mechanisms and pathways that have been involved in the processes (see below). 
biomolecular markers are 'carbon skeletons, and the position, number, and stereochemistry of the double bonds' of carbon (Ibid. 79-84; see also Evershed 2008b).

The biomarkers approach focuses on the correlation of lipid molecular components preserved within organic residues in pottery with biomolecules present in modern-day plant and animal tissues. While the composition of animal and plant lipids in contemporary materials is well established, the effect of degradation, e.g., chemical, microbiological or physical, on these individual lipids and their distributions during vessel use and burial (diagenesis) needs to be studied continuously (see Spangenberg et al. 2006; Eerkens 2007; Gregg et al. 2009; Gregg, Slater 2010). The complex mixtures which originate from the degradation of lipids (specifically those with unsaturated components) are difficult to interpret and can often lead to an incorrect characterisation of the origin of the residues (Stacey 2009).

Although the conceptualisation of 'archaeological biomolecular markers' remains unchanged, their terminology and typology have become more precisely elaborated recently (Evershed 2008b.898; Regert 2011). The markers are recognised as: 'biomarkers' that correspond to native molecules relating to natural sources (animal and plant fatty acids, sterols); 'anthropogenic transformation markers' that relate to chemical transformations induced by different human activities (e.g., heating vessels and pyrolysis); 'natural degradation markers' formed by the natural decay of initial 'biomarkers', or 'transformation' markers during deposition by chemical or biochemical processes; and 'migration markers', known as contaminants, that relate to components migrating from sediment to archaeological organic residues (Regert 2011.185; see also Erkens 2007).

By combining the complementary data of all molecular markers, and their chemical characteristics and isotopic values, it is possible to detect animal fats in pottery and to identify their main types (body fats of ruminants and non-ruminants, dairy products, and marine and freshwater resources), their biosynthetic origins, their diagenesis through natural burial and aging, and alteration under cooking conditions. The application of the 'archaeological biomarker concept' has required analytical techniques that can achieve molecular-level resolution. While gas chromatography combined with mass spectrometry (GC-MS) is recognised as the most useful technique for lipids individual identification and distribution

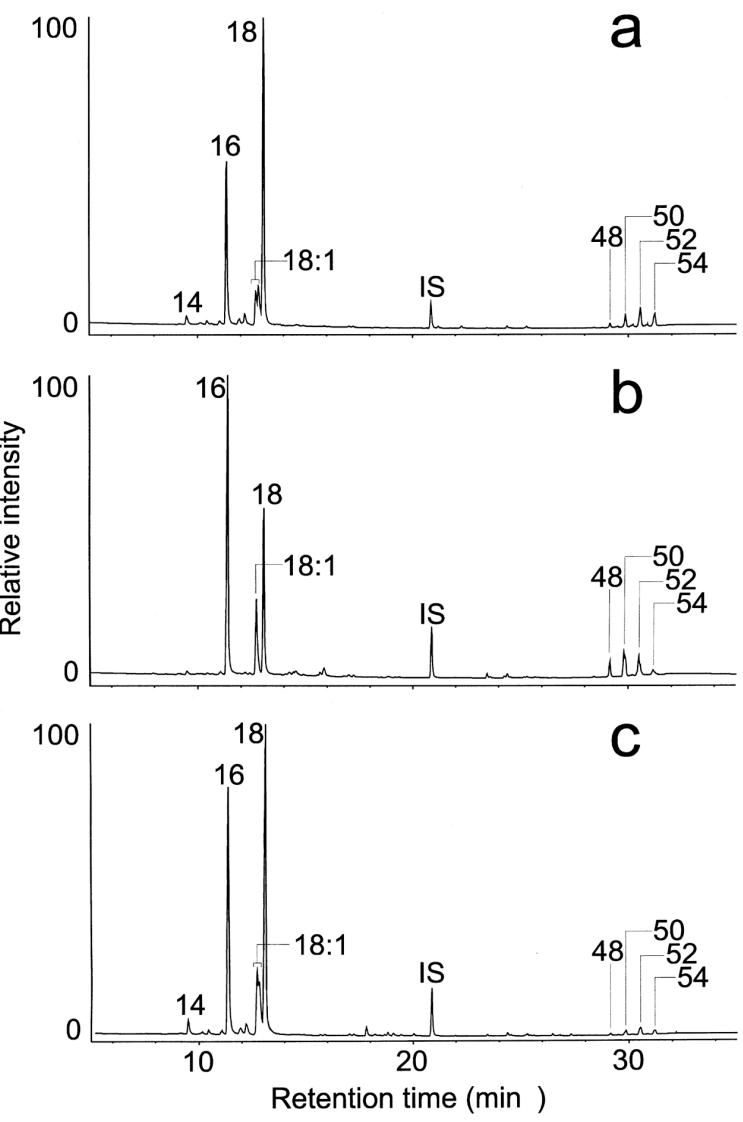

Fig. 7. High-temperature gas chromatograms of the total lipid extracts from "Medieval pottery samples (Leicester): lamp (a), 'dripping' dish (b) and cauldron (c). Peak identities 14:0 (myristic), 16:0 (palmitic), 18:0 (stearic) are saturated fatty acids. The 18:1 is octadecenoic (oleic) acid. The IS is internal standard of n-tetratricontane. The 48, 50, 52, 54 are triacylglycerols (TAGs)" (reprinted from Mottram et al. 1999.Fig. 1, copyright 1999, with permission from Elsevier).

within a mixture in lipids matrices, gas chromatography-combustion-isotope ratio mass spectrometry (GC-C-IRMS) has been used to detect biomarkers isotopic structures and $\delta 13 \mathrm{C}$ values, and to record the biochemical history of each diagnostic components.

From 'bulk stable isotope' to 'compound-specific stable isotope' analysis

As presented above the identification of food components in organic residue in a ceramic matrix is complicated due to degradation processes that occurred during vessel use and burial. Lipids are preserved in 'low concentrations in highly degraded and complex matrices' because of chemical and micro-biological processes of degradation and alteration that include hydrolysis, oxidation, polymerization, condensation, cyclization or microbial degradation (Evershed 2008a; Regert 2011.178). Degrad- 

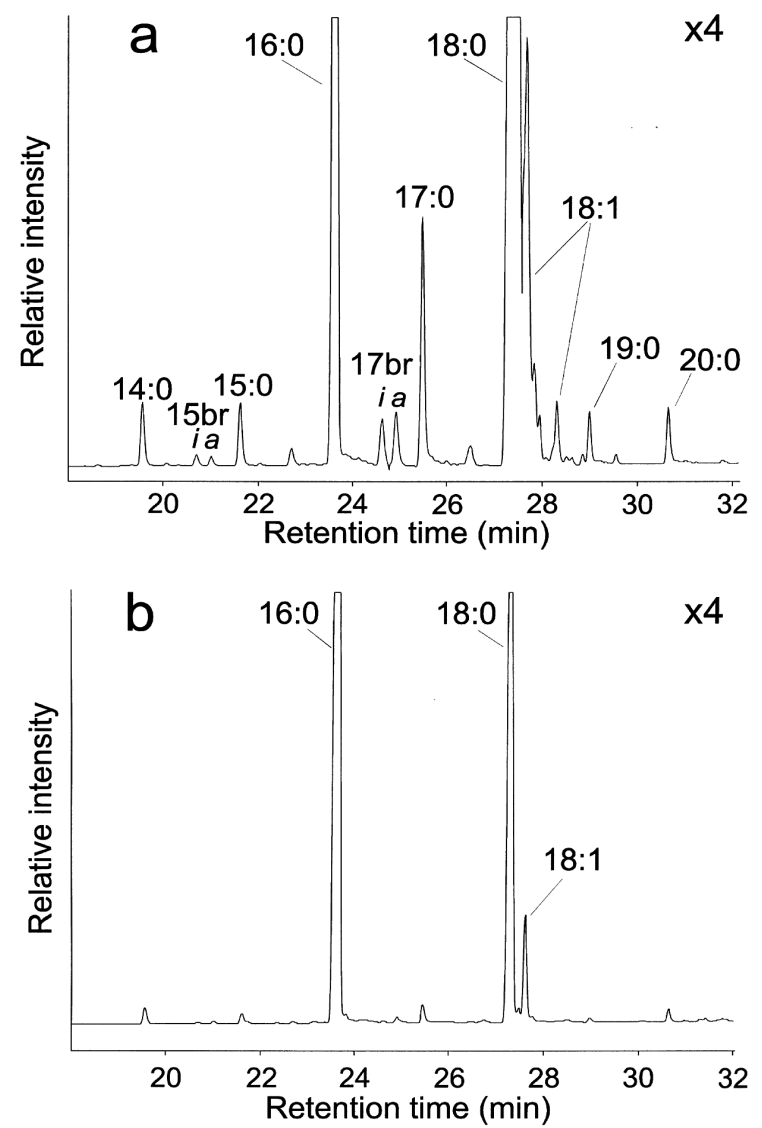

Fig. 8. Gas chromatograms of fatty acid methyl esters recovered from Medieval (Leicester) 'dripping dish' (a) and a lamp (b) (reprinted from Mottram et al. 1999. Fig. 2, copyright 1999, with permission from Elsevier).

ed animal fats, which are the most commonly identified 'biomolecular constituent', are characterised by a recognisable distribution of FAs, MAGs, DAGs and intact TAGs. Because of degradation and alteration they might exhibit great similarities in the chromatographic pattern of total lipids extract. The analytical work thus focused on the carbon isotope $(\delta 13 \mathrm{C})$ compositions of individual biomarkers, e.g., FAs, TAGs and wax esters (Evershed et al. 1994; 1997a).

Evershed (2009.397) suggested a number of 'compelling' reasons for an analytical and interpretative shift from bulk carbon $\left(\delta^{13} \mathrm{C}\right)$ and nitrogen $\left(\delta^{15} \mathrm{~N}\right)$ isotope compositions to the carbon isotope $\left(\delta^{13} \mathrm{C}\right)$ values of individual biomolecular markers, i.e. 'compound-specific $\delta^{13} \mathrm{C}$ values on individual lipids'. The reasons mainly relate to the facts that structurally similar biochemical components can derive from sources exhibiting different stable isotopic signatures, and that 'complementary use of structurally diagnostic biomarkers' together with their compoundspecific stable isotope values can provide informa- tion on a metabolic process (i.e. to distinguish adipose and milk fats). The compound-specific stable isotope analysis is thus to provide accurate stable isotope value(s) for a specific component(s) of what is likely to be a biochemically complex matrix preserved in pottery to be compared to modern reference samples.

Advances in high temperature gas chromatography (GC) analysis of total lipid extract, and the development of appropriate methodologies of lipid extraction and purification at the beginning of the 1990s made it possible to analyse the main biomarker components of animal fats, including TAGs, FAs, and sterols. Work on the assessment of transformation and degradation markers ran parallel to experimental work on animal fats from replica ceramic vessels and degradation experiments (for an overview, see Evershed 2008a). Evershed's team introduced an internal standard in the procedure for quantifying different components of extracts (i.e. molecular markers); they later became used in various laboratories, sometimes with minor modifications. However, many important components in total lipid extract (TLE) from ceramic matrices cannot be analysed directly by GC. They have to be chemically modified, or derivatised first to generate molecular markers and their isotopic signatures.

The trimethylsilylation sampling protocol (resulting in TMS derivatives) is associated with high-tem-

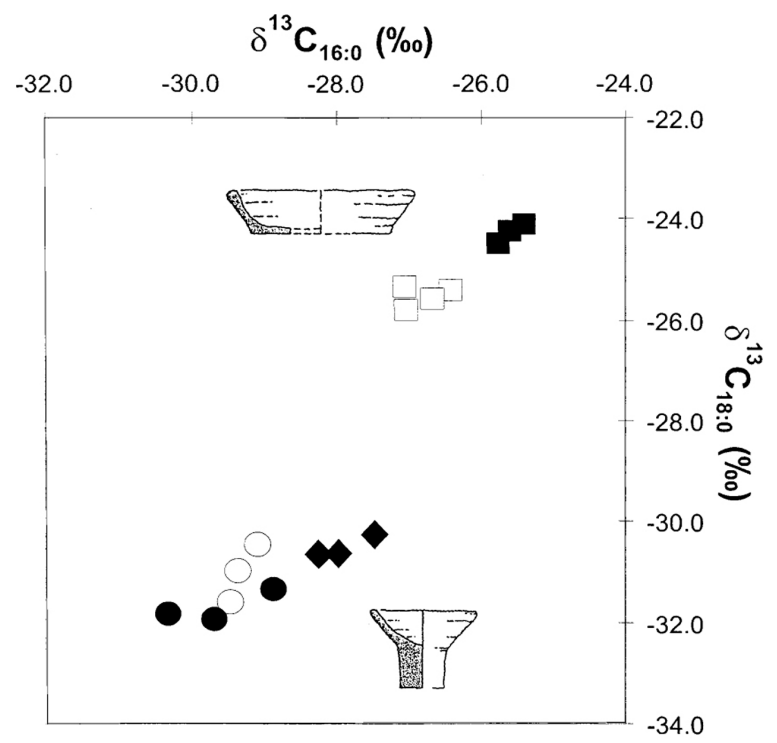

Fig. 9. Plot showing the $\delta 13 C$ values of $C_{16: 0}$ and $C_{18: 0}$ FAs "form Medieval lamps $(\bigcirc)$ and dripping dishes (घ) and from modern reference animal fats [cattle $(\diamond)$, sheep (๑), and pig (口)]" (reprinted with permission from Evershed et al. 2002.Fig. 10, copyright 2002 American Chemical Society). 
perature gas chromatography (HT GC) and gas chromatography-mass spectrometry (HT GC-MS) techniques. They are basic investigative techniques focused on the initial detection of molecular markers, 'intact acyl lipids' or fatty acids like FAs, TAGs, DAGs, MAGs and wax esters that provide the partial gas chromatogram profile of the total lipid extract preserved in the ceramic matrix (Evershed et al. 1990; Charters et al. 1993; 1995) (Fig. 4).

The parallel gas chromatograph-combustion-isotope ratio mass spectrometer (GC-C-IRMS) technique enables the compound-specific isotope $\left(\delta^{13} \mathrm{C}\right)$ analysis of individual molecular markers extracted from bulk organic materials. It is necessary to transform the FAs via the chemical process of esterification to FAMEs (fatty acid methyl esters), which play a substantial role in identification of isotopic signature of individual biomarkers and to differentiate their sources (Fig. 5). GC-C-IRMS has proven especially powerful in determining and studying the $\delta 13 \mathrm{C}$ values of FAs as biomarkers for animal fats in pottery matrices, and in distinguishing ruminant (e.g., sheep/goat and cattle) and non-ruminant (pig) body fats for the major old world domesticates (for an overview, see Evershed 2009; Regert 2011).

The initial application of this approach, which combines the biomarker and the compound-specific $\delta 13 \mathrm{C}$ values of individual markers, was related to dietary plant lipids analysis. It was carried out by linking a gas chromatograph (GC) to the isotope ratio mass spectrometer (IRMS) used for stable isotope measurement (Evershed et al. 1991; 1994; 1999.22). The molecular structures present in organic residues in the ceramic matrix were correlated with those known to be present in modern-day vegetables, and 'likely to have been exploited in antiquity'. The gas chromatographic profiles for the total lipid extracts of a medieval cooking pot show the biomarker distribution, which consists of FAs and their derivatives, and the wax esters hydrolysed into $\mathrm{C}_{29}$ and $\mathrm{C}_{31}$ alkanes, $\mathrm{C}_{29}$ ketones and $\mathrm{C}_{29}$ alcohol. The distribution of alkanes and ketones corresponds well with those in cabbage leaves (Brassica oleracea) boiled in an experimental replica vessel (Charters et al. 1997). The $\delta^{13} \mathrm{C}$ values for the $\mathrm{C}_{29}$ alkanes and ketone are consistent with those of higher plant leaf waxes, as shown by the similarity to the values obtained for the contemporary wild Brassica $(-35.8 \%$ o $\pm 0.1)$ within the accepted limits of precision $( \pm 0.3 \%)$.

However, further studies of cooking of leafy vegetables of an Early Bronze Age cooking vessel show that

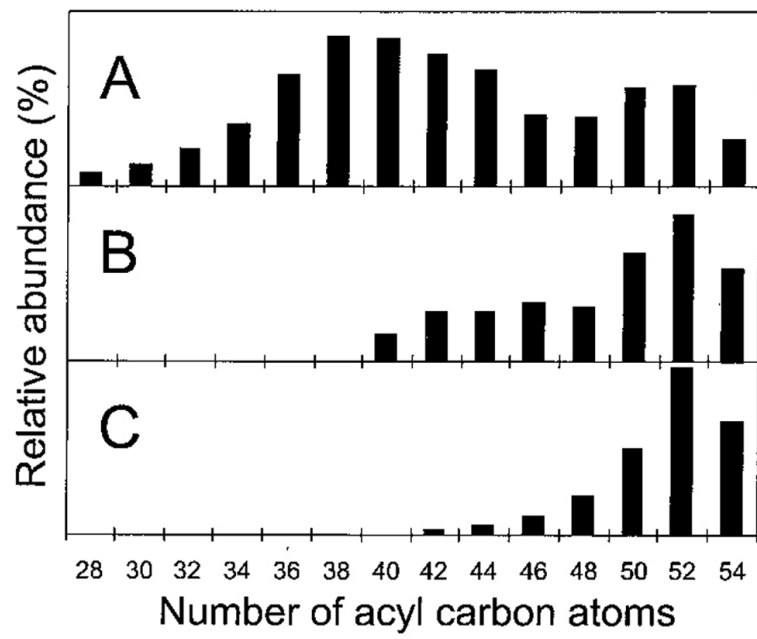

Fig. 10. TAGs distributions in (A) fresh milk, (B) milk absorbed in ceramic vessel and degraded in the laboratory under oxic conditions for 90 days, and (C) fresh ruminant (ovine) adipose fat. The distributions were determined by high-temperature GC of total lipid extracts (from Dudd, Evershed 1998. Fig. 1, reprinted with permission from AAAS).

the three major saturated long-chain ketones (the $\mathrm{C}_{31}, \mathrm{C}_{33}$ and $\mathrm{C}_{35}$ ) in the total lipids extract have $\delta^{13} \mathrm{C}$ values of $-26.8,-26.5$ and $-25.9 \%$ respectively (Raven et al. 1997). These compounds are too enriched $(c .10 \%)$ in $13 \mathrm{C}$ to be derived from epicuticular leaf waxes of Brassica oleracea $(-35.4 \% 0)$. Two major FAs $\left(\mathrm{C}_{16: 0}\right.$ and $\left.\mathrm{C}_{18: 0}\right)$ in the same extract have ${ }^{13} \mathrm{C}$ values of $-25.5 \%$ and $-26.6 \%$ o similar to those of ketones. This similarity suggests that since cooking vessels were continuously heated, ketones have formed by condensation of fatty acid moieties derived from fats absorbed into the ceramic matrix during vessel use. (Fig. 6).

Laboratory experiments involving heating $\left(\leq 300^{\circ} \mathrm{C}\right)$ of either TAGs or FAs acids embedded in a ceramic matrix showed that during the heating of fats at high temperatures such mixtures of long-chain ketones can form readily. These findings indicate 'anthropogenic transformation markers' and the close similarity of the ketones produced by the pyrolysis of acyl lipids and those biosynthesised by higher plants (Evershed et al. 1999.23).

The next approach combining the biomarker and the compound-specific $\delta^{13} \mathrm{C}$ values of individual markers was related to the question of the origin of animal fats. Animal fats present greater challenges, because the major components, polyunsaturated fatty acids, TAGs that compose approx. 95\% of fresh animal fats, rarely survive in pottery residuals, leaving mainly undiagnostic fatty acids. 
Fig. 11. Plot of the $813 \mathrm{C}$ values of the $C_{16: 0}$ and $C_{18: 0}$ FAs of the lipid extracts "from potsherds from (A) West Cotton (late Saxon to early medieval) and (B) Stanwick (Iron Age-Romano-British). The archaeological fats (solid circles) cluster near the reference adipose and milk fats (bovine and ovine). In the case of West Cotton, nonruminant (porcine) adipose fats have also been identified. The mixing curves (dashed lines) have been calculated to illustrate the $\delta 13 \mathrm{C}$ values that would result from the mixing of ovine/bovine and porcine fats in the vessels. The encircled fields encompass the ranges for reference animal fats, with the ranges crossing at the arithmetic

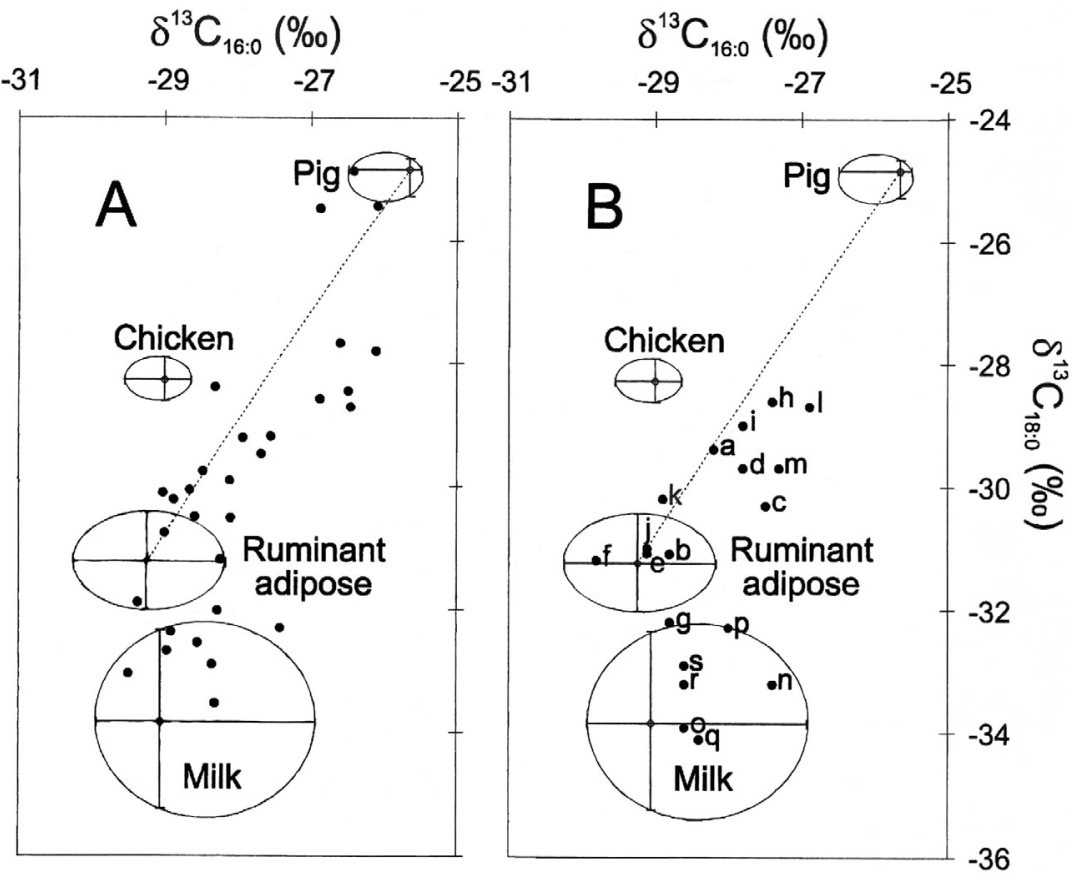
mean. The numbers of different reference fats analyzed were as follows: pig adipose fat, 4; ruminant adipose fat, 9 (3 cow and 6 sheep); chicken adipose fat, 8 ; milk fat, 7 (6 cow and 1 sheep). All the animals were raised on $\mathrm{C}_{3}$ diets. The more depleted $\delta{ }^{13} \mathrm{C}$ values for the $\mathrm{C}_{18}$ fatty acid in the milk fats arises through routing of a large proportion of fatty acids directly from the diet (after biohydrogenation) to milk production. The ${ }^{13} \mathrm{C}$ values for the fatty acids in the reference fats have been corrected for the post- Industrial Revolution effects of fossil fuel burning, which has decreased the $\delta{ }^{13} \mathrm{C}$ value of atmospheric $\mathrm{CO}_{2}$ by $1.2 \%$ since the middle of the $19^{\text {th }}$ century. The letters adjacent to the points in (B) correlate with the triacylglycerol distributions ... and correspond to the following types of domestic archaeological vessels: $\mathbf{a}, \mathrm{b}, \mathrm{e}, \mathrm{f}$, $\mathrm{h}$ through $\mathrm{m}, \mathrm{p}, \mathrm{r}$, and $\mathrm{s}$ are jar-form vessels of various sizes; $\mathrm{c}$ is a mortaria; $d$ is a ceramic lid; $\mathrm{g}$ and $\mathrm{n}$ are flanged and wide bowls, respectively; and $i, o$, and $q$ are small dishes. There was no obvious correlation between vessel form and the type of fat they contained. Analytical precision is $\pm 0.3 \%$ " (from Dudd, Evershed 1998.1479, Fig. 2, reprinted with permission from AAAS).

It was shown, however, that it is possible to identify animal fats if the stable isotopic compositions of the FAs generated via the hydrolysis of TAGs are determined. For example, the $\delta^{13} \mathrm{C}$ values of saturated $\mathrm{C}_{16: 0}$ and $\mathrm{C}_{18: 0}$ FAs that survive in degraded animal fats can be used to differentiate their sources. Ruminant and non-ruminant fats can be separated, and ruminant adipose fats distinguished from dairy fats, due to metabolic differences between the different animals and carbon sources utilised in the biosynthesis of different fat types (Evershed $2008 b$. 899-900).

The first attempt to distinguish animal fats focussed on medieval ceramic vessels of two different shapes, with various functions as lamps and 'dripping dishes'. The HT GC chromatographic profiles for the total lipid extracts (using derivatisation sampling protocol) showed biomarker distributions, which consist of a great quantity of saturated $\mathrm{C}_{16: 0}$ and $\mathrm{C}_{18: 0}$ and unsaturated $\mathrm{C}_{18: 1}$ FAs. MAGs and DAGs were present only in very low quantities, and it seemed that the hydrolysis was almost completed. The small amount of TAGs remained intact in ceramic matrices, as if they had been protected from degradation (Fig. 7). Although the extracts of all the vessels contained the same major saturated and unsaturated FAs $\left(\mathrm{C}_{16: 0}, \mathrm{C}_{18: 0}\right.$ and $\left.\mathrm{C}_{18: 1}\right)$ there were clear differences in the relative proportions. In the lamps, the $\mathrm{C}_{18: 0}$ FA was more abundant than the $\mathrm{C}_{16: 0}$ component. In contrast, the dripping dishes had more $\mathrm{C}_{16: 0}$ (Evershed et al. 1997b; Mottram 1999).

Clear differences were also apparent in the distributions of FAs identified by their FAME mass spectra for the two vessel types. The gas chromatograms show a series of branched iso- and anteiso FAs, with 15 and 17 carbon atoms $\left(\mathrm{C}_{15 \text { br }}\right.$ and $\left.\mathrm{C}_{17 b r}\right)$, known to be formed in the gut by thermophilic bacteria synthesis. While they have a strong biological signature in lamps, they were not found in the 'dripping dishes' (Evershed et al. 1997b; 1999; Dudd, Evershed and Gibson 1999; Mottram 1999) (Fig. 8).

A parallel electron ionisation mass spectrometry (EI) associated with dimethyl disulphide (DMDS) and io- 

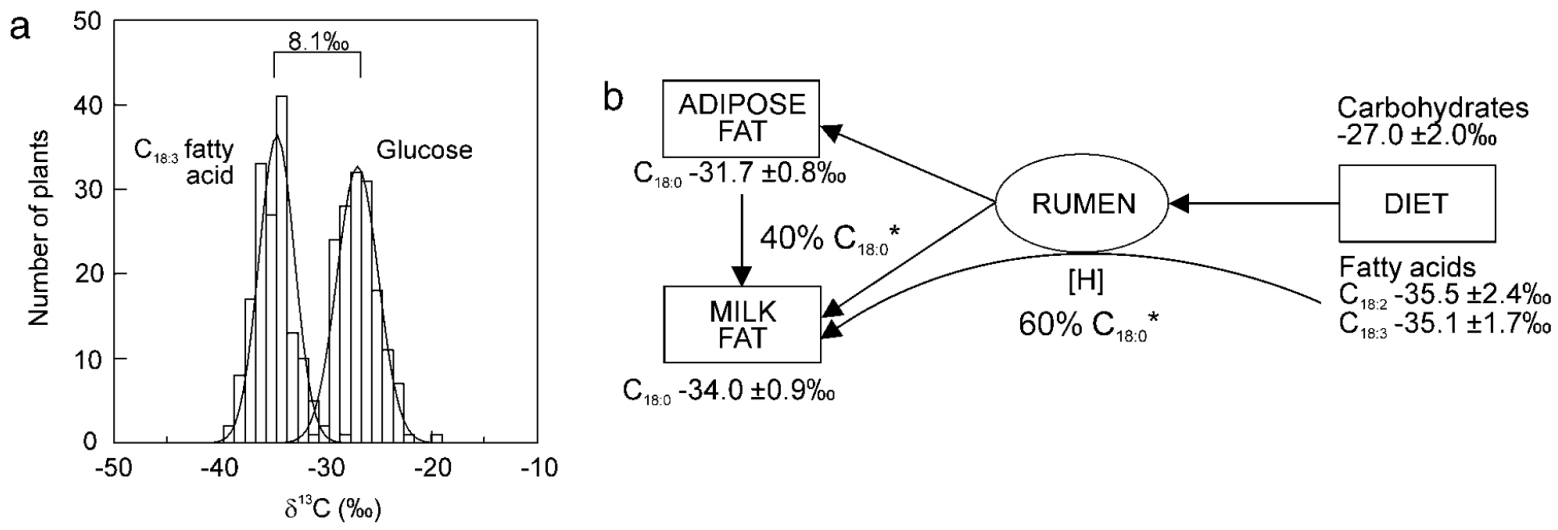

Fig. 12. (a) "Histogram of the $\delta^{13} \mathrm{C}$ values of $\mathrm{C}_{18: 3}$ fatty acids and glucose extracted from plants. The histogram of the $\delta 13 \mathrm{C}$ values of the major fatty acids and carbohydrates of 166 modern plants demonstrates that there is an $8.1 \%$ mean difference in the $\delta 13 \mathrm{C}$ values of $\mathrm{C}_{18: 3}$ fatty acid (mean $=-36.3 \%$ ) and glucose (mean $=-28.2 \%$ ) which is the basis of the difference in the $\delta 13 \mathrm{C}$ value of the $\mathrm{C}_{18: 0}$ fatty acid in dairy and milk fat. This difference in $\delta 13 \mathrm{C}$ value between lipids and carbohydrates is seen in both $\mathrm{C}_{3}$ and $\mathrm{C}_{4}$ plants." (b) "Diagram showing the routing of dietary fatty acids and carbohydrates in the rumen, adipose tissue and mammary gland of the ruminant animal. $60 \%$ of the $\mathrm{C}_{18: 0}$ in ruminant milk is directly incorporated from the diet following biohydrogenation of unsaturated fatty acids in the rumen (marked by asterisk), and reflects the inability of the mammary gland to biosynthesise $\mathrm{C}_{18: 0}$, and the remaining $40 \%$ is rerouted from adipose tissue and is comprised of carbon originating from dietary glucose and fatty acids. The 2.3\% mean difference in the $\delta^{13} \mathrm{C}$ values of $\mathrm{C}_{18: 0}$ in ruminant adipose tissues and dairy fats can be seen graphically in Fig. 12a" (from Copley et al. 2003.Fig. 1, copyright 2003, The National Academy of Science).

dine in diethyl ether treatment of FAMEs has revealed the existence of two kinds of monounsaturated fatty acid $\mathrm{C}_{18: 1}$ (oleic acid) distributions. While the single monounsaturated octadecenoic acid $\mathrm{C}_{18: 1 \Delta^{9}}$ was identified in 'dripping dishes', a more complex composition characterised by a mixture of positional isomers of octadecenoic acid with a double bond located at different positions $\mathrm{C}_{18: 1 \Delta, 11,13,14,15,16 \text { was }}$ identified in lamps (Evershed et al. 1997b; Mottram et al. 1999). It was suggested that this difference in fatty acid distribution reflects different origins of

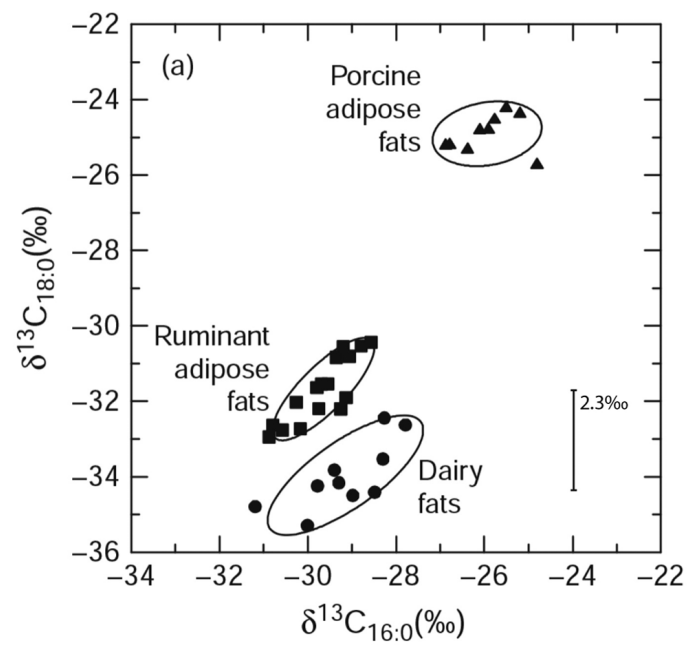

animal fats related to different diets and variations in animal metabolisms. While in ruminant animals (sheep and cattle), biohydrogenation of dietary fats occurs in the rumen, resulting in the formation of several positional $\mathrm{C}_{18: 1}$ isomers, in non-ruminant monogastric animals (pigs) a single isomer is present (Evershed et al. 1997b; 2002.664).

The origins of animal fats were further studied by GC-C-IRMS analysis of $\delta^{13} \mathrm{C}$ values of individual free FAs, palmitic $\left(\mathrm{C}_{16: 0}\right)$ and stearic $\left(\mathrm{C}_{18: 0}\right)$, and by corre-

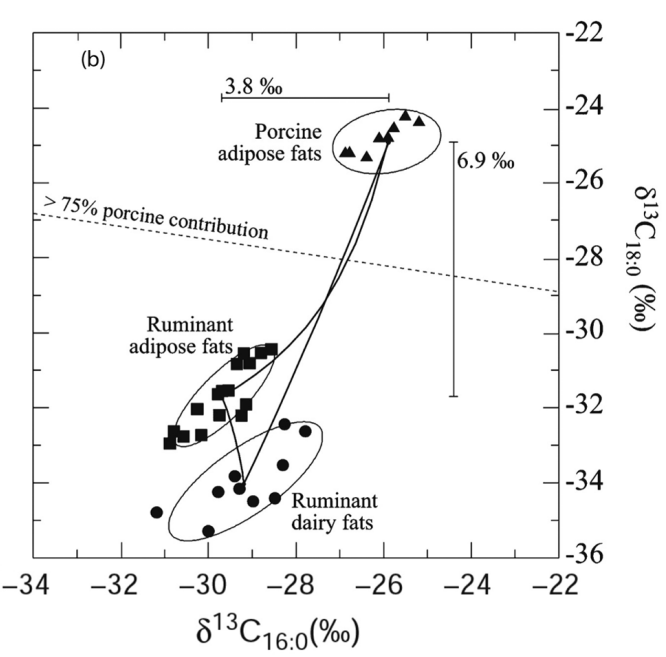

Fig. 13. Scatter plot showing the $2.3 \%$ mean difference in the $813 \mathrm{C}$ values of $C_{18: 0}$ in ruminant adipose tissues and dairy fats, and the 6.9\% mean difference in porcine body fat and ruminant adipose fat (reprinted and modified from Evershed 2009.Fig. 14.18a and Mukherjee et al. 2007.Fig. 3, with permission from Antiquity Publications Ltd). 
lation with modern reference fats considered to be the major domesticated species in the medieval period in the United Kingdom such as pigs, sheep and cattle. The analysis was supplemented with laboratory degradation experiments of those fats deposited in modern potsherds (Evershed et al. 1997b).

The $\delta^{13} \mathrm{C}$ values of $\mathrm{C}_{16: 0}$ and $\mathrm{C}_{18: 0}$ FAs clearly indicated that these two types of vessel contained two kinds of animal fat (Fig. 9). The FAs in the lamps were depleted in $13 \mathrm{C}$, having higher $\delta^{13} \mathrm{C}$ values compared to the 'dripping dishes'. Individually, in the lamps the $\delta^{13} \mathrm{C}$ value of palmitic $\mathrm{C}_{16: 0}$ was higher compared to the $\delta^{13} \mathrm{C}$ value in stearic $\mathrm{C}_{18: 0}$, whereas in the 'dripping dishes' the situation was reversed. The FAs in the latter cluster near the reference body porcine fats, while the former plot close to the values obtained for modern non-ruminant fats (Evershed et al. 1997b; 2002; Mottram et al. 1999). The $\delta 13 \mathrm{C}$ values were consistent with the biomarker compositions determined by GC-MS, as the set of FAs identified in lamps was consistent with ruminant fats, while those determined in 'dripping dishes' were characteristic of monogastric animals.

\section{From biomolecular to stable isotope markers: from meat to milk}

Subsequent studies focused on ruminant and non-ruminant fats and possible changes in patterns of animal exploitation and dietary practices in prehistory. Among the existing extraction protocols and instrumental analytical methods mentioned above, a number of precise chemical criteria were suggested for use in distinguishing between the residues of animal fats preserved in ceramic matrices. These criteria relate to both biomolecular and isotopic markers and were listed in order: "( $i$ ) the positional isomers of monounsaturated fatty acids; (ii) the abundances of odd-carbon number $\left(C_{15: 0}\right.$ and $\left.C_{17: 0}\right)$ iso- and anteiso- branched-chain fatty acids; (iii) fatty acid and triacylglycerol distributions; and (iv) the ${ }^{13} \mathrm{C}$ values of the major saturated fatty acids $C_{16: 0}$ and $C_{18: 0}$, determined by GC-combustionisotope ratio MS (GC-C-IRMS)" (Dudd, Evershed 1998a.1479). Stephanie Dudd and Richard Evershed postulated that while bulk stable isotope studies allow the detection of remnant fats in either carbonised food re- sidues or residues absorbed in pottery, the compound-specific $\delta^{13} \mathrm{C}$ measurements allows the differentiation of nonruminant (omnivores) and ruminant (herbivores) animals' fats, and a distinction between adipose and dairy fats in ruminants. They hypothesised that one major category of fat that has to be detected in pottery is that derived from milk, and that just as with body fats, the processing of milk would result in the absorption of fat by the ceramic matrices. They presumed it would be easy to detect dairy fat, because of the presence of shortchain $\left(\mathrm{C}_{4}\right.$ to $\left.\mathrm{C}_{14}\right)$ saturated FAs biomolecular markers, the main components of fresh milk. However, they failed to detect them in any lipid extracts from
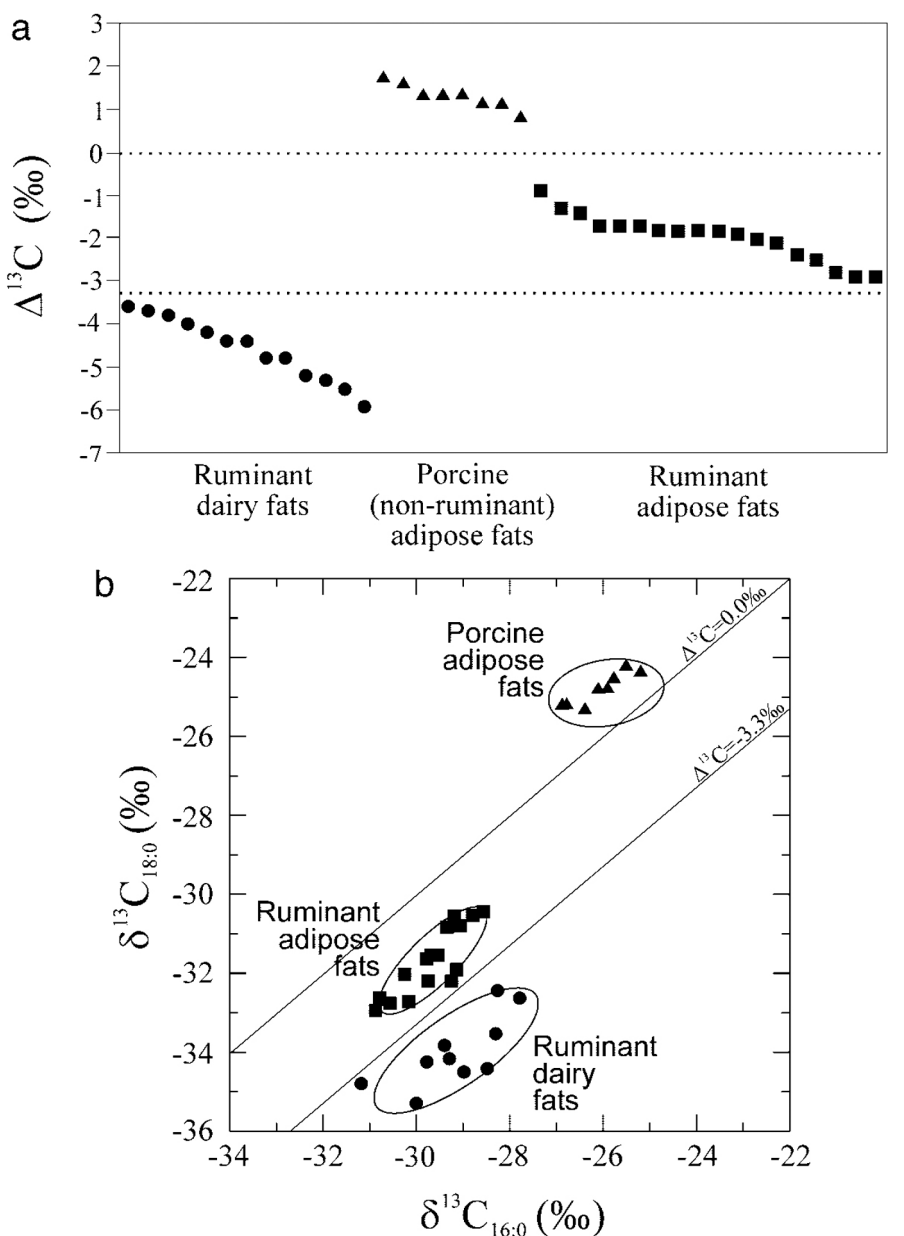

Fig. 14. "Plot of the difference in the $\delta 13 \mathrm{C}$ values of the $\mathrm{C}_{18: 0}$ and $\mathrm{C}_{16: 0}$ fatty acids ( $=\Delta^{13} \mathrm{C}$ value) obtained from the modern reference fats (a). Plot of the $\delta 13 \mathrm{C}$ values of $\mathrm{C}_{16: 0}$ and $\mathrm{C}_{18: 0}$ fatty acids of modern reference fats (b). The three fields correspond to $P=\mathbf{0 . 6 8 4}$ confidence ellipses calculated for the $\delta 13 \mathrm{C}$ values of the domesticates known to comprise the major component of prehistoric economies in Britain. All of the animals were raised on $\mathrm{C}_{3}$ diets. The $\delta 13 \mathrm{C}$ values obtained from the modern reference materials have been adjusted for post-Industrial Revolution effects of fossil fuel burning by the addition of $1.2 \%$. Analytical precision is $\pm 0.3 \%$ " (reprinted from Copley et al. 2003.1526, Fig. 2, copyright 2003, The National Academy of Sciences). 

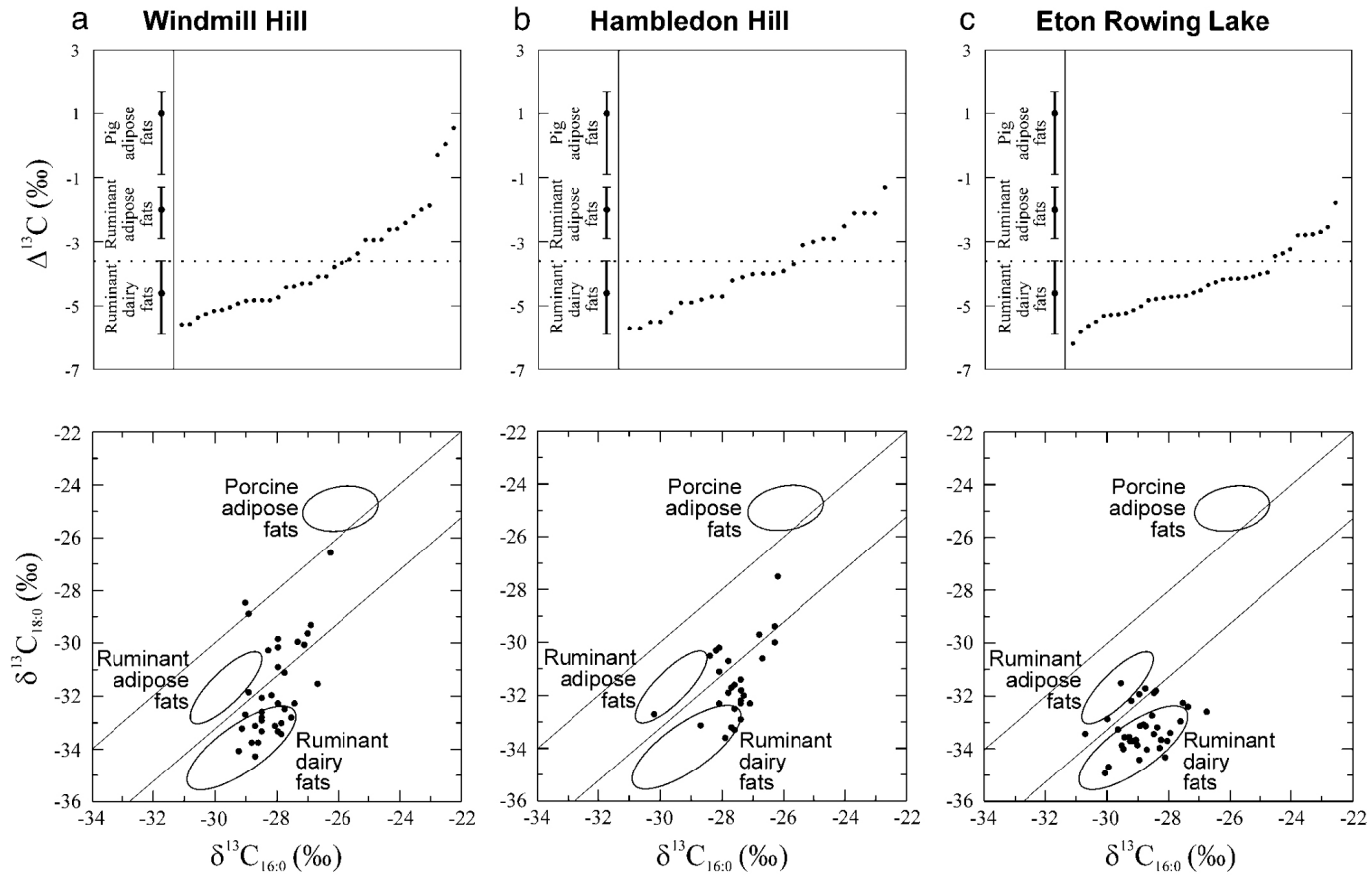

Fig. 15. Plots of the $\delta 13 C$ values of $C_{16: 0}$ and $C_{18: 0}$ FAs and $\delta 13 C$ values of lipid extracts from Neolithic pottery from of Windmill Hill (a), Hambledon Hill (b), and Eton Rowing Lake (c) sites in the United Kingdom. The fields and ranges corresponding to the modern reference fats have served "to classify the lipid extracts". Extracts that plot between the reference ellipses have been recognized to be "indicative of the mixing of commodities in antiquity" (reprinted from Copley et al. 2003.Fig. 3, copyright 2003, The National Academy of Sciences).

pottery. They ran a laboratory experiment to prove that their inability to detect dairy fats must have been related to milk processing and to compositional alteration through decay during burial. Meanwhile, they examined the existing biomolecular markers, e.g., TAGs distributions of both, milk fat from fresh milk and of ruminant body fat after decay in the laboratory when absorbed into unglazed replica pottery (Dudd et al. 1998). The results showed that when released from TAGs by hydrolysis, the shortchain FAs are more water soluble than their longchain counterparts. Over a period of 90 days, the distribution of FAs in milk was transformed into a distribution similar to that of the adipose fat. They observed the same pattern in lipid extracts from ceramic matrices (Fig. 10). They realised that molecular analyses alone do not allow dairy fats to be distinguished from body fats, or ruminant from non-ruminant fats.

As most of the lipids extracted from pottery matrices are reduced to $\mathrm{C}_{16: 0}$ and $\mathrm{C}_{18: 0}$ FAs, the components of hydrolysed TAGs are often the only surviving lipids of degraded degradation and/or biological hydrolysis during deposition. Dudd and Evershed thus focused on the isotopic markers, the $\delta 13 \mathrm{C}$ values of $\mathrm{C}_{16: 0}$ and $\mathrm{C}_{18: 0}$ FAs in lipids extracted from different pottery assemblages. The residuals from Late
Saxon - Early Medieval and Iron Age - Romano-British pottery matrices were analysed first. The results showed that ruminant fats in pottery could be divided into two groups, one with low $\delta 13 \mathrm{C}$ values for $\mathrm{C}_{18: 0}$ (Dudd, Evershed 1998) (Fig. 11). They noticed that the isotope values of this group are similar to those they obtained on modern ruminant milk fats. They suggested, therefore, that the "data show that milk and adipose fats from animals raised on similar diets are separable on the basis of the comparison of the $\delta^{13} \mathrm{C}$ values of $C_{16: 0}$ and $C_{18: 0}$ fatty acids and that this provides the basis for determining the presence of milk fat in archaeological pottery" (Dudd, Evershed 1998.1480). As the biochemical evidences of processing of animal products in various archaeological vessels correspond well with the composition of the bone assemblage from the site, Richard Evershed et al. (2002.665) suggested further that the application of compound-specific stable isotope analyses "to pottery from prehistoric periods is beginning to reveal important cultural biases in the exploitation of animal products".

Dudd and Evershed (1998) proposed that the isotopic higher values for FAs in ruminant body relate to a subtle difference in the way in which the $\mathrm{C}_{16: 0}$ and $\mathrm{C}_{18: 0}$ acids are synthesised in two types of fat. Body tissues are able to make both $\mathrm{C}_{16: 0}$ and $\mathrm{C}_{18: 0} \mathrm{FAs}$, 

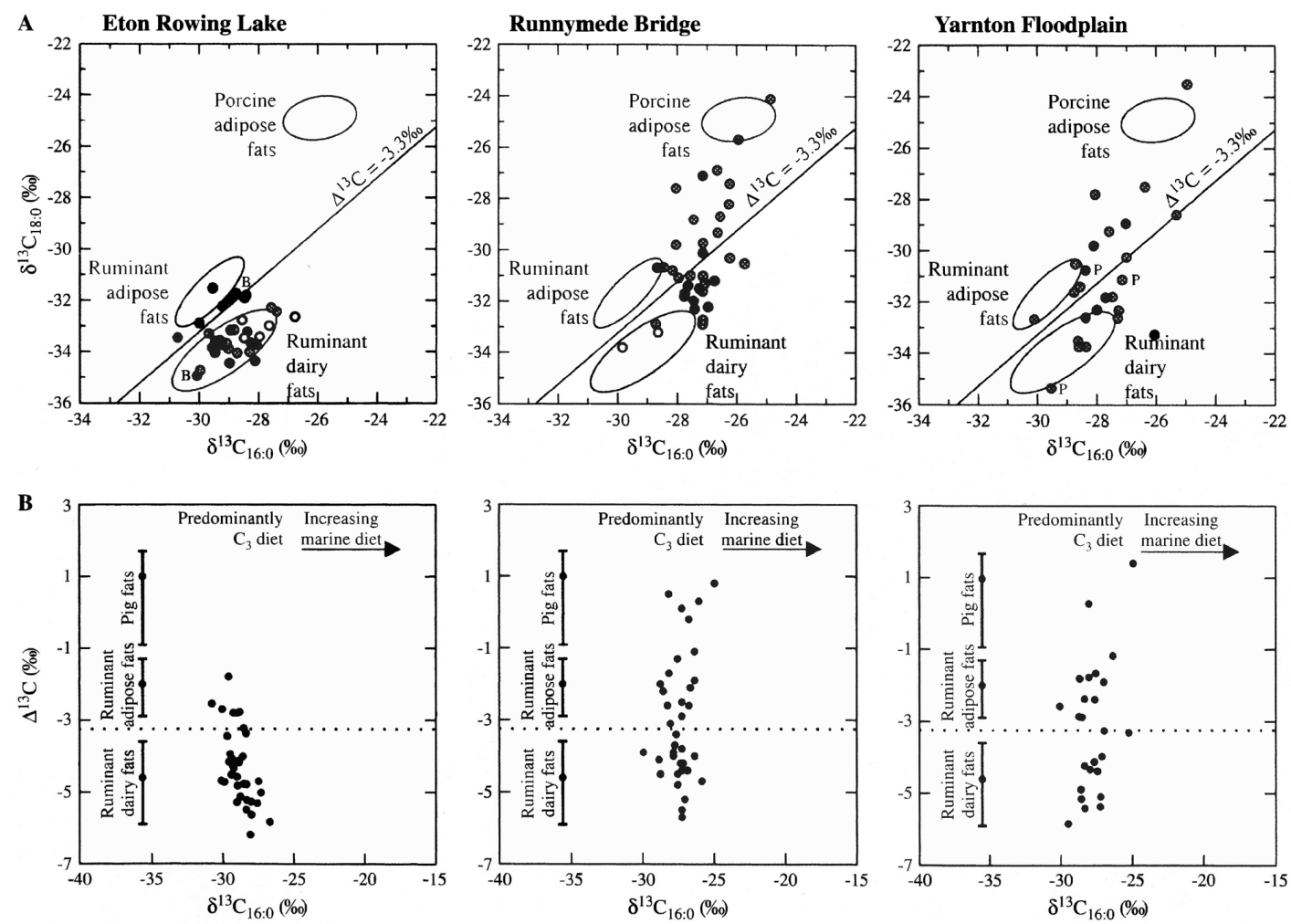

Fig. 16. "(A) Plot of the $\delta 13 \mathrm{C}$ values of the FAMEs of $\delta 13 \mathrm{C}_{16: 0}$ and $\delta 13 \mathrm{C}_{18: 0}$, prepared from lipid extracts from the six pottery assemblages. The ellipses indicate the $\delta 13 \mathrm{C}$ values of the reference animal fats, based on which the archaeological extracts are classified. Sherds plotting in between the ellipses represent the mixing of animal products in the vessel. $\Delta 13 \mathrm{C}\left(=\delta 13 \mathrm{C}_{18: 0}-\delta 13 \mathrm{C}_{16: 0}\right)$ values of lower than $-3.3 \%$ indicate dairy fats. The black filled circles represent extracts containing TAG distributions indicative of degraded adipose fats. The open circles represent those with typical degraded dairy fat TAG distributions, whilst the circles with crosses within them represent sherds that yielded no TAGs. A 'P' adjacent to the circle denotes that plant lipids were also detected, whilst a ' $B$ ' represents the presence of beeswax. (B) $\Delta^{13} C$ values of the extracts plotted against their $\delta \mathbf{C}_{16: 0}$ values. The further the sherds plot to the right, then the greater the marine component of the animals' diet. The reference materials are represented by their ranges and mean $\Delta^{13} \mathrm{C}$ values" (reprinted from Copley et al. 2005c.527, Fig. 3, copyright 2005, with permission from Elsevier).

using acetate and other substrates derived from carbohydrates contained in the diet. This process involves an isotopic shift that results in the $\delta^{13} \mathrm{C}$ value of the synthesised biomolecule being 1-2\%o higher than that of the dietary carbon. On the other hand, the mammary gland can synthesise $\mathrm{C}_{16: 0}$, but not $\mathrm{C}_{18: 0}$. It obtains them from FAs contained in the ingested plants, most of which are unsaturated, like $\mathrm{C}_{18: 1}, \mathrm{C}_{18: 2}$ and $\mathrm{C}_{18: 3}$. The biohydrogenation process in the rumen converts about $40 \%$ of them to saturated $\mathrm{C}_{18: 0}$ FAs. This conversion does not result in an isotopic shift. Therefore, the $\delta^{13} \mathrm{C}$ value of the $\mathrm{C}_{18: 0}$ in milk, or in any dairy product, is slightly lower than that in body tissue.

A few years later Mark Copley et al. (2003) confirmed that a range of chemical criteria, like saturated fatty acid compositions, double-bond positions, TAGs distributions, and $\delta^{13} \mathrm{C}$ values, can be used to assign the origins of fats to domesticated animals (sheep goats, cattle, and pigs) in prehistory. As the critical distinction between meat and milk fats is possible by determining $\delta^{13} \mathrm{C}$ values in the $\mathrm{C}_{18: 0}$, the analytic focus turned to the study of the $\delta^{13} \mathrm{C}$ values of individual FAs and to the differences in values for ruminant adipose and diary fats, and for non-ruminant fats in prehistoric and modern animals.

The ${ }^{13} \mathrm{C}$ values of the $\mathrm{C}_{16: 0}$ and $\mathrm{C}_{18: 0}$ FAs from 16 ruminant adipose and 10 dairy fats, and 8 non-ruminant (porcine) body fats from modern animals that were raised on strict $\mathrm{C}_{3}$ diets were calculated. The results show that stearic $\mathrm{C}_{18: 0}$ acid in milk fat has a $\delta^{13} \mathrm{C}$ value $\approx 2.3 \%$ o lower compared to the same $\mathrm{FA}$ in adipose fat due to the biohydrogenation process in the rumen. The differences in $\delta 13 \mathrm{C}$ values of the $\mathrm{C}_{16: 0}$ and $\mathrm{C}_{18: 0}$ between porcine body fat and ruminant adipose and milk fats are $\approx 4.6 \%$ and $\approx 6.9 \%$ o respectively (Copley et al. 2003.1525-1526; Mukherjee 2007.745) (Figs. 12 and 13). 

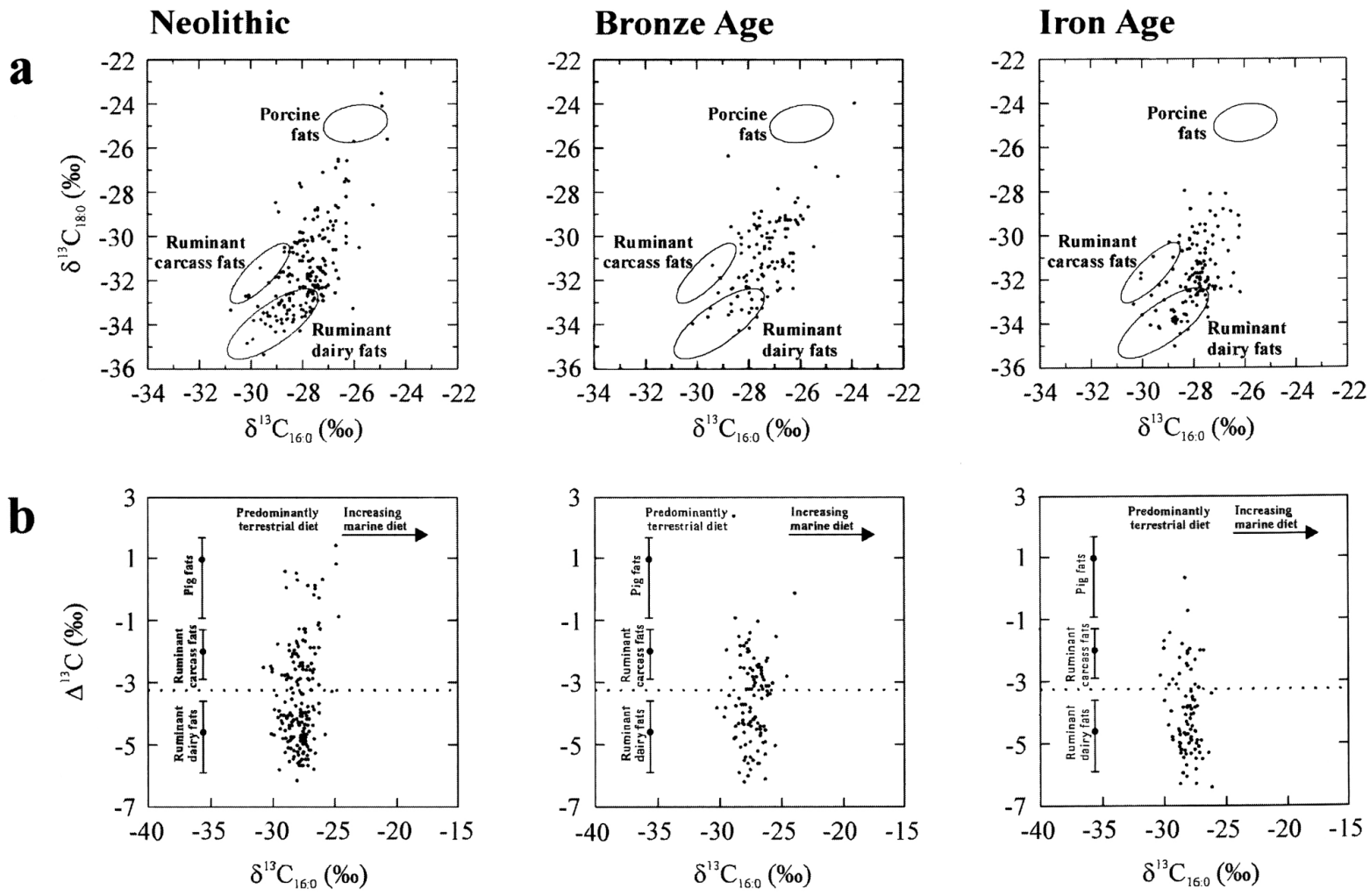

Fig. 17. "(a) Plot of the $\delta^{13} \mathrm{C}$ values of the $\mathrm{C}_{16: 0}$ and $\mathrm{C}_{18: 0}$ fatty acids extracted from Neolithic, Bronze and Iron Age pottery. Pottery plotting in between the ellipses represent the mixing of animal products in the vessel ... $\Delta^{13} \mathrm{C}$ values of lower than $-3.3 \%$ are a further method of identifying dairy fats. Further the sherds plot to the right, higher the percentage of marine derived food was utilised in the animal's diet" (reprinted from Copley et al. 2005.Fig. 3, with permission from Antiquity Publications Ltd).

In order to remove any exogenous influences, such as variability in diet, season and other environmental factors, and retain only the metabolic influences on the $\delta^{13} \mathrm{C}$ values of the $\mathrm{C}_{16: 0}$ and $\mathrm{C}_{18: 0}$ correction factor $-\Delta^{13} \mathrm{C}$ proxy was introduced. ${ }^{2}$ It was expressed as $\Delta^{13} \mathrm{C}=\delta^{13} \mathrm{C}_{18: 0}-\delta^{13} \mathrm{C}_{16: 0}$ (Copley et al. 2003) (Fig. 14).

The $\Delta^{13} \mathrm{C}$ proxy values were calculated for the three fat types of modern animal, and the species were grouped together by using 'confidence ellipses'. The distributions of ${ }^{13} \mathrm{C}$ values for the major $\mathrm{FAs}_{\mathrm{C}} \mathrm{C}_{16: 0}$ and $\mathrm{C}_{18: 0}$ of modern reference fats (bovine, ovine and porcine adipose and bovine milk) are marked with the ellipse positions within the graphs. The three positions correspond to confidence ellipses calculated for the ${ }^{13} \mathrm{C}$ values of the domesticates 'recognized to comprise the major component of prehistoric economies in Britain' (e.g., pig, sheep/goat and cattle). All of the animals were raised on $\mathrm{C}_{3}$ diets. The $\delta^{13 \mathrm{C}}$ va-

2 Within a grazing food web (chain) the energy and nutrients move from plants to the herbivores consuming them, and to the humans, who consume the flesh or milk of those animals. During the complex process of plant photosynthesis two biochemical reactions, the carbon fixation and fractionation determine the main plant photosynthetic pathways. The $\mathrm{C}_{3}$ pathway or cycle is marked by the first organic carbon compound that contains a molecule with three carbon atoms. In $\mathrm{C}_{4}$ pathway it has four carbon atoms. All the plants (vegetables, fruits, wheat and grasses) in temperate ecosystems use the $\mathrm{C}_{3}$ cycle. Plants in tropics environments (millet, maize, sugar cane and savanna grasses), adapted to hot and arid environments, use the $\mathrm{C}_{4}$ photosynthetic cycle. They differ in the levels of stable isotopic fractionation while assimilate atmospheric $\mathrm{CO}_{2}$ into tissues. Plants selectively incorporate carbon into tissues taking up proportionally less ${ }^{12} \mathrm{C}$ and ${ }^{13} \mathrm{C}$ than is available in their carbon reservoir in the atmosphere. In the process of conversion of atmospheric $\mathrm{CO}_{2}$ into organic compounds (carbohydrates, lipids and fatty acids, amino acids, and fats and oils) plants prefer to take in ${ }^{12} \mathrm{C}$ over ${ }^{13} \mathrm{C}$ and thus create different ratio of stable isotopes values $\left({ }^{13} \mathrm{C}\right)$ than the atmosphere has. The $\mathrm{C}_{3}$ plants show higher isotopic fractionation and $\delta^{13} \mathrm{C}$ values range from -34 to $-22 \%$. $\mathrm{C}_{4}$ plants have lower isotopic fractionation and thus $\delta 13 \mathrm{C}$ values range within -16 and $-9 \%$. Because carbon isotopic fractionation between the tissues of the consumer and its diet is very small, from $1 \%$ to $2 \%, \delta^{13} \mathrm{C}$ values of animals are directly linked to those of plants consumed by the herbivores at the beginning of the trophic chain. The negative $\delta^{13} \mathrm{C}$ values lower than $-22 \%$ o thus indicate that the food that the individual has consumed comes mainly from $\mathrm{C}_{3}$ plants, as well as from the flesh (fats) or milk of animals that subsisted on $\mathrm{C}_{3}$ plants only (Vogel 1993; DeNiro M. J., Epstein S. 1978). 

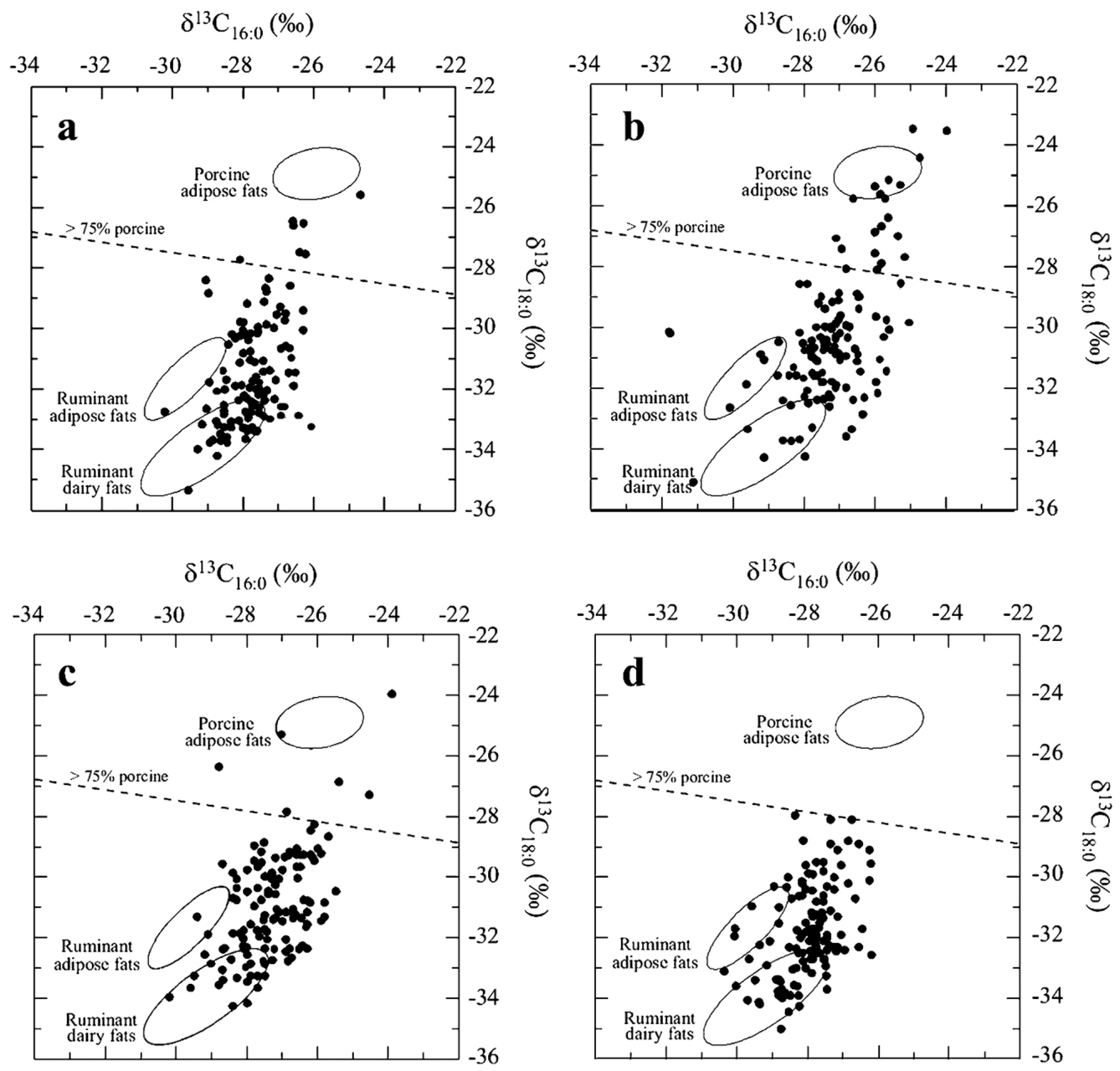

Fig. 18. Scatter plots of $\delta 13 \mathrm{C}$ values of $C_{16: 0}$ and $C_{18: 0}$ FAs from lipid extracts of "all (a) Neolithic (not including Grooved Ware), (b) Grooved Ware, (c) Bronze Age and (d) Iron Age vessels" in the United Kingdom (reprinted from Mukherjee et al. 2007.Fig. 4, with permission from Antiquity Publications Ltd).

lues for modern FAs have been corrected for post-Industrial Revolution effects of fossil fuel burning. By assuming that the isotopic fractionation in the preindustrial biogeochemical carbon cycle was determined by today's known photosynthetic mechanisms and metabolic pathways, we could expect the $\delta 13 \mathrm{C}$ ratios of $\mathrm{C}_{16: 0}$ vs. $\mathrm{C}_{18: 0}$, and $\mathrm{C}_{18: 0}$ vs. $\mathrm{C}_{18: 1}$ co-variation for plants and consumers at that time to be shifted by $1.2 \%$ toward more positive $\delta^{13} \mathrm{C}$ values (Copley et al. 2003.1526). Spangenberg et al. (2006.9) have corrected the $\delta^{13} \mathrm{C}$ ratios of $\mathrm{C}_{16: 0}$ and $\mathrm{C}_{18: 0}$ FAs of modern reference fats by $1.6 \%$ which they believe to be a more accurate comparison between their archaeological data from a Neolithic site in Switzerland and modern reference fats. The correction was based on a study of the isotopic composition of $\mathrm{CO}_{2}$ recorded in Antarctic ice cores.

The ${ }^{13} \mathrm{C}$ proxy of the main FAs vary from -5.9 to $+1.8 \%$. While values lower than $-3.3 \%$ indicate ruminant dairy fats (cattle, sheep and goat milk and the production and consumption of milk products), values lower than $-1.1 \%$ o suggest ruminant body fat (cattle, sheep and goat meat processing and consumption). Values close to 0 and higher indicate non-ruminant body fats (porcine meat processing and consumption). Ruminant dairy fats are thus distributed between -3.3 and $-6 \%$, and adipose between -1.1 and $-3.2 \%$ (Copley at al. 2003.1526).

The $\Delta^{13} \mathrm{C}$ proxy approach was first applied to lipids extracted from 930 ceramic vessels from 14 prehistoric sites in the United Kingdom (UK). They represent the largest regionally based pottery assemblage to be studied. The classification of lipids was performed through a comparison of plots of the isotopic composition of FAs from ceramic matrices and the reference animal fat ellipses and their $\Delta^{13} \mathrm{C}$ values. They are presented as scatter plots of the $\delta 13 \mathrm{C}$ values obtained from the $\mathrm{C}_{16: 0}$ and $\mathrm{C}_{18: 0}$ FAs extracted from pottery matrices along the plots of 'confidence ellipses' that indicate the $\delta^{13} \mathrm{C}$ values of the 


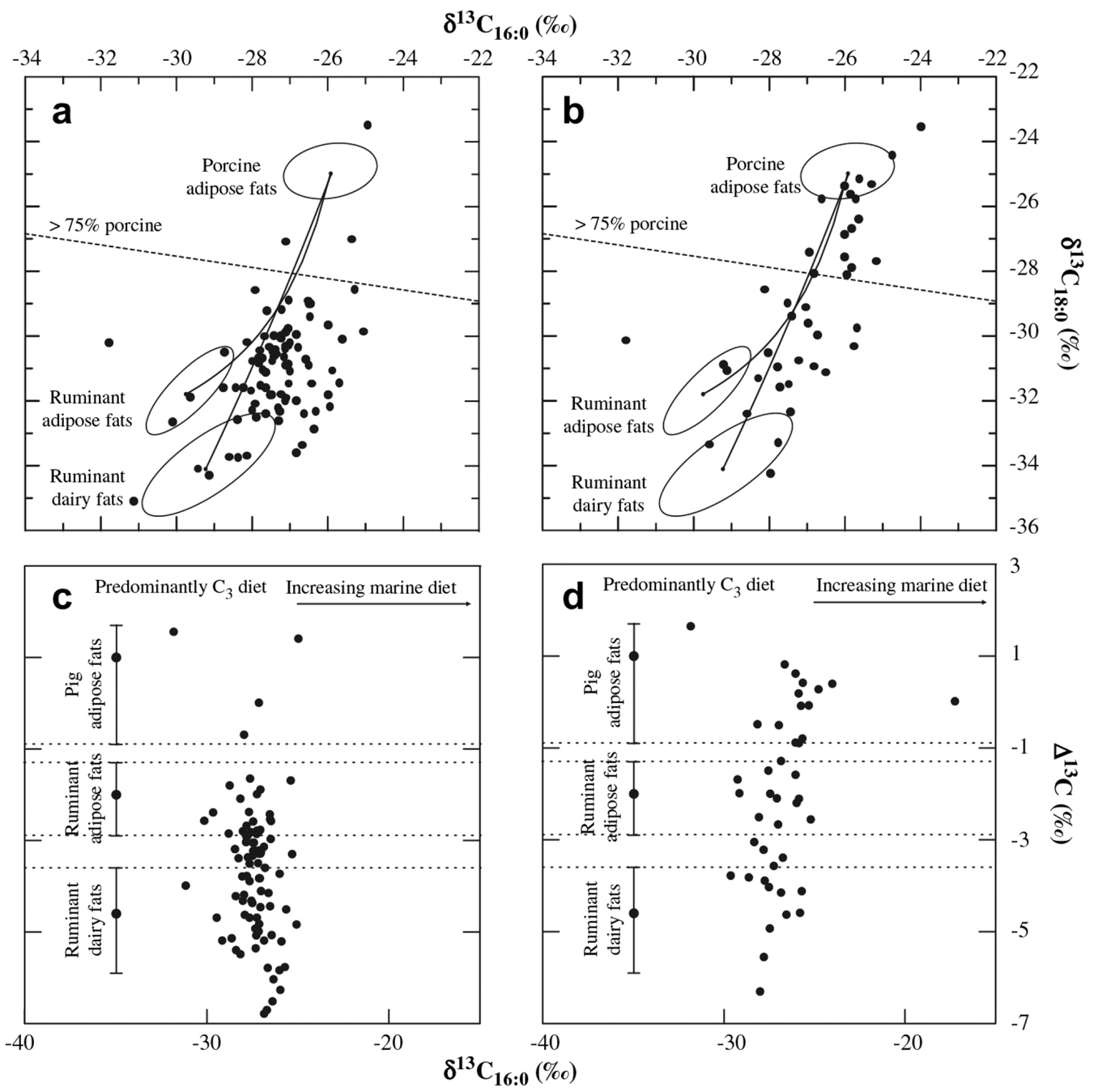

Fig. 19. Scatter plots of $\delta 13 C$ values of $C_{16: 0}$ and $C_{18: 0}$ FAs "from (a) domestic Grooved Ware, (b) ceremonial/non-domestic Grooved Ware, and plots of $\Delta^{13} \mathrm{C}$ values for all (c) domestic Grooved Ware and (d) ceremonial/non-domestic Grooved Ware" in Neolithic in United Kingdom (reprinted from Mukherjee et al. 2008.Fig. 9, copyright 2008, with permission from Elsevier).

reference animal fats from which the extracts are classified. The $\Delta^{13} \mathrm{C}$ proxy distributions are graphed separately (Fig. 15).

The dairying trajectory has been systematically charted from the Neolithic to the Iron Age across the British Isles (Copley et al. 2005a; 2005b; 2005c; Cramp $2014 a$ ). The results show site-to-site variation, although at some sites the intensity of dairying was high, and no mixing of ruminant and non-ruminant fats was evident in any of the vessels (Fig. 16). However, the processing of ruminant animal products (both adipose and dairy fats) strongly prevailed through the prehistoric periods. Very few of the $\delta^{13} \mathrm{C}$ values plot within, or in the vicinity of, the reference pig body fat ellipses, suggesting that vessels used only to process porcine products were rare. At a few sites, mixing of porcine and ruminant adipose fats in the vessels was evident (Copley et al. 2005) (Fig. 17).
Copley et al. (2005a.528) suggested that about 50\% of the extracts that contained significant quantities of lipids can be classified as predominantly dairy fats. On the other hand, they point out that very few of the extracts plot within the reference isotopic values of pig body fats. There was even no evidence of the processing of porcine products in vessels from sites where bones were preserved, suggesting that porcine products were processed by other methods (e.g., spit roasting) that did not involve the pottery they analysed (Copley 2005.898; 2005a.528).

The identification of the origin of dairy fats residue has been related to the question of whether fats arise through the processing of milk or milk products, such as yoghurt, or represent residues of the use of butter. The laboratory experiments performed on replica vessels indicate that milk degrades much faster than butter, probably because of the presence of 

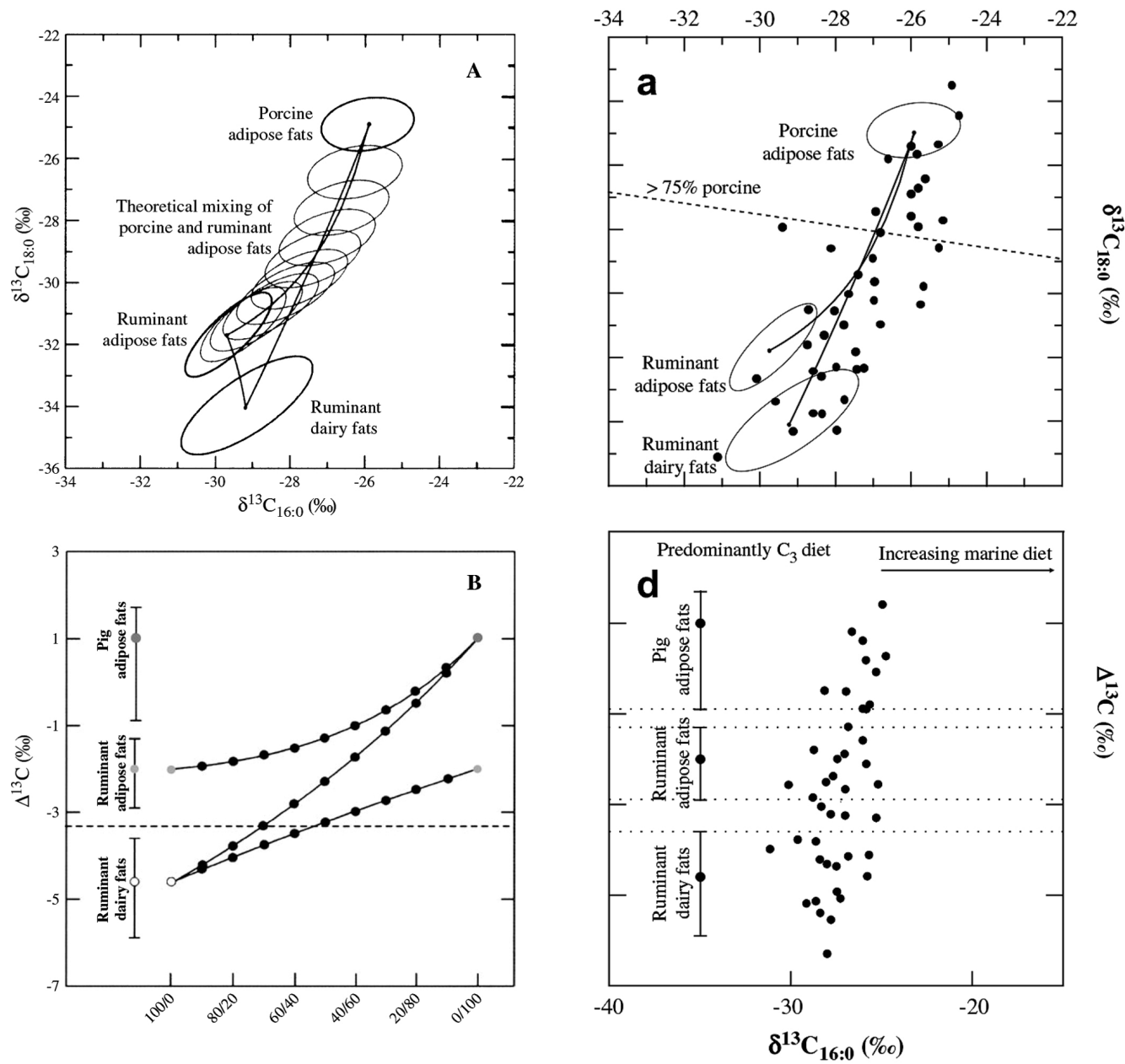

Fig. 20. (A) The theoretical mixing of animal fats. "The labelled ellipses are generated from the reference animal fats, and the minor ellipses correspond to the theoretical fields that would result from the mixing of the respective fats (each ellipse represents a 10\%increase/decrease in the specific commodities). The lines are the actual mixing curves joining the centroids of the respective fields. (B) The theoretical effect on the $\Delta{ }^{13} C\left(=\delta 13 C_{18: 0}-\delta 13 C_{18: 0}\right)$ values of mixing the specific fats as in (A). The reference materials are represented by their ranges and mean $\Delta{ }^{13} \mathrm{C}$ values." Curves from the porcine adipose ellipse to the ruminant dairy and adipose ellipses and between the ruminant dairy and adipose ellipses represent theoretical $\delta 13 C$ values for mixtures of these fats. Extracts plotting above the dotted line contain a $75 \%$ or greater contribution of porcine fat (a,d) (reprinted from Copley et al. 2005b.508, Fig. 2, copyright 2004, with permission from Elsevier; and Mukherjee et al. 2008.2068, Fig. 6, copyright 2008, with permission from Elsevier).

proteins and carbohydrates that are excellent nutrients for soil micro-organisms. In contrast, butter is composed of pure lipids and is not a suitable substrate for microbial growth. It was concluded, therefore, that the accumulation of dairy fats in several prehistoric vessels may have derived from 'the processing of large amounts of butter fat, probably over extended periods of time' (Copley et al. 2005.905).

While there were no differences in vessel form or actual use in the Neolithic, it was demonstrated that dairy products were generally processed in vessels with smaller rim diameters than those used for cooking meat products in the Bronze Age. There were differences in vessel use, type and form, and rim diameter in the Iron Age (Copley et al. 2005).
The subsequent analyses based on lipids extracts from 385 vessels from 16 sites from the UK showed that $16 \%$ of late Neolithic Grooved Ware vessels contained 'significant proportions of porcine fat, and half of these were used to process solely porcine products'. The pottery from preceding Peterborough and Impressed Wares sites, while predominantly used to process dairy products, also showed evidence of the processing of porcine products, but only $7 \%$ of the extracts were composed of predominantly porcine fats (Mukherjee et al. 2007). To put these results in a wider prehistoric context in Britain, they were incorporated into an accumulated dataset of $\delta 13 \mathrm{C}$ values for pottery lipid residues from prehistoric sites analysed by Copley et al. (2005) (Fig. 18). 

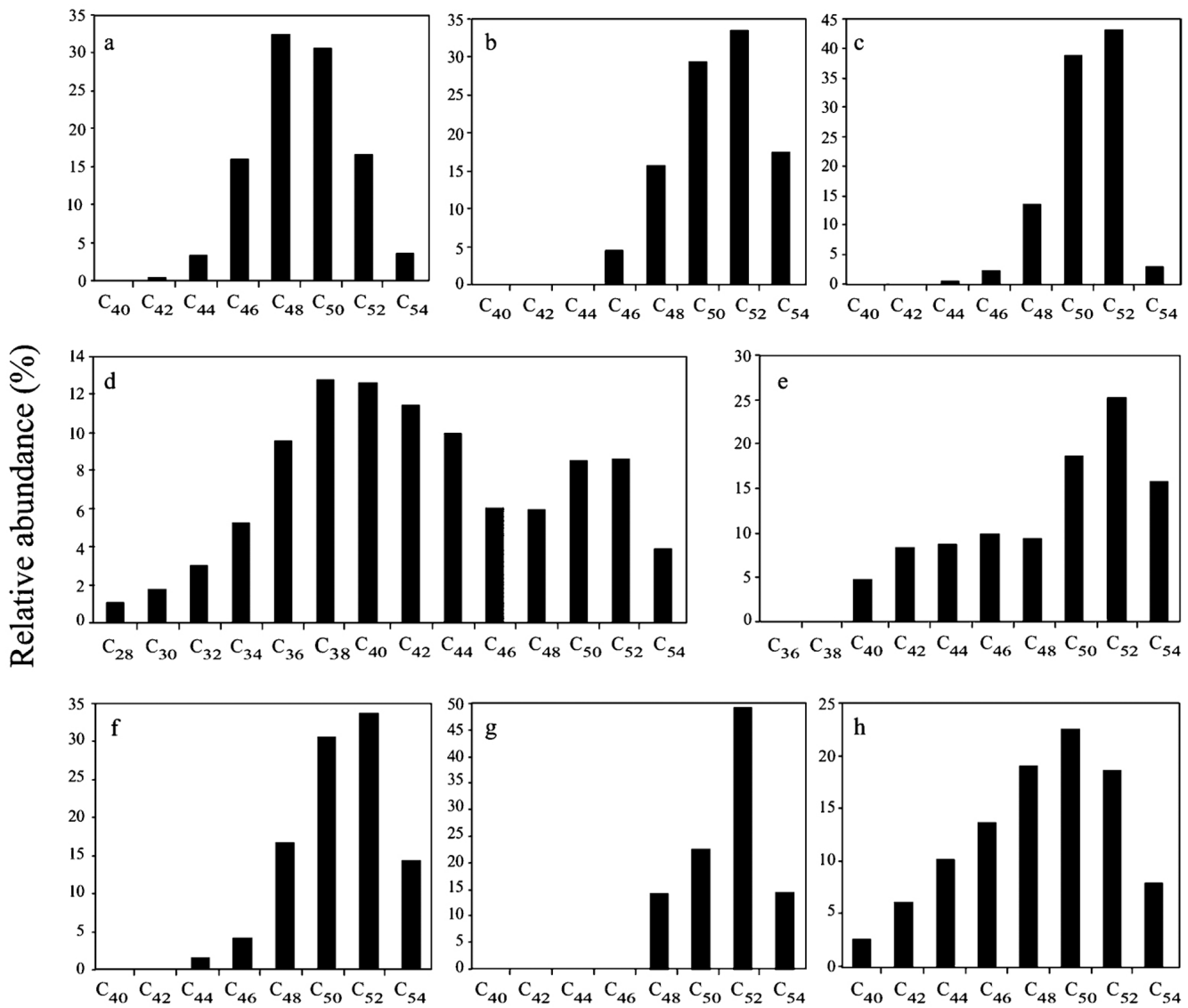

Acyl carbon number

Fig. 21. Histograms "of typical saturated acyl carbon number distributions in modern reference animal fats: (a) cow adipose fats, (b) sheep adipose fat, (c) pig adipose fats, (d) fresh milk, (e) milk degraded for 90 days; and animal fats extracted from prehistoric pottery: (f ) ruminant adipose fat, (g) porcine adipose fat, (h) ruminant dairy fat" (reprinted from Mukherjee et al. 2007.Fig. 2, with permission from Antiquity Publications Ltd).

Site-to-site analysis of Grooved Ware sites showed that the processing and consumption of pig or pig products was more important at non-domestic, ceremonial sites than at domestic settlement sites. This may be due to 'the suitability of the pig to be raised and slaughtered for large-scale feasting events' at ceremonial sites or it could relate to a special significance of pigs to the Grooved Ware people', allowing them to be consumed only at certain places or by specific people (Mukherjee, Gibson and Evershed 2008) (Fig. 19).

A broad discrepancy between the $\delta^{13} \mathrm{C}$ distributions of lipid extracts and principal ellipses of reference animal fats representing domesticates known to have been raised in prehistory in the UK can be seen from the plots. Very few of the extracts plot within, or in the vicinity of, the reference ruminant and non-ruminant body fat fields. It was suggested that those embedded between the ellipses indicate the mixing of these fats in the vessels (Copley 2005.897) (Fig. 17).

Theoretical mixing curves have been calculated to illustrate the effect of vessel re-use and the processing of mixtures of foods. Each ellipse in Figure 20A "represents the effect of mixing a specific percentage of each of the respective commodities[3]. The resultant mixing lines display curved trends due to differences in the relative abundances of the fatty acids in the animal fats, and hence their influence on the overall $\delta^{13} \mathrm{C}$ values... [W]henever a lipid extract is classified, it is necessary to refer to the extract as being of predominantly dairy/ruminant adipose/porcine adipose origin rather than simply being of ruminant adipose origin, for instance. Furthermore, it is likely that classifications based on both of these plots depend upon the ex-

3 The term commodity is broadly accepted "to designate all kind of raw or transformed natural substance that has been exploited by ancient communities" (Regert 2011.184). 

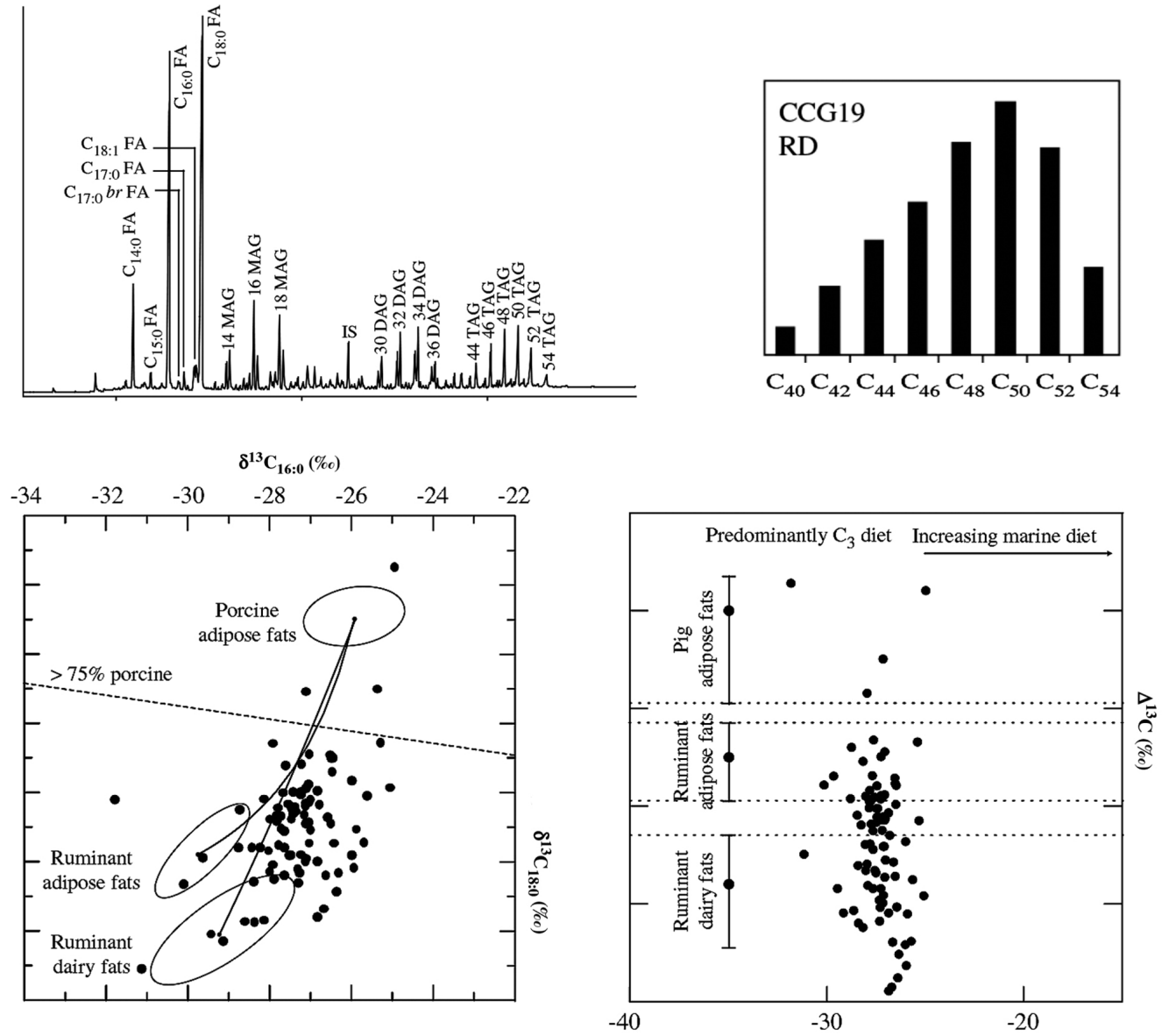

Fig. 22. Partial high temperature gas chromatograms of total lipid extract, and histogram of TAGs carbon number distributions indicative of ruminant dairy from the same extract. They both correlate to scatter plot showing the ${ }^{13} \mathrm{C}$ of $C_{16: 0}$ and $C_{18: 0}$ FAs, and $\Delta^{13} C$ proxy measured for domestic Neolithic Grooved Ware pottery in UK (reprinted from Mukherjee et al. 2008. Figs. 4, 5, 9, copyright 2008, with permission from Elsevier).

tent of vessel re-use in antiquity... The three principal ellipses from the $\delta^{13} \mathrm{C}$ values of the reference animal fats representing the domesticates known to have been raised in British prehistory ... The corresponding $\triangle^{13} \mathrm{C}$ values ... are shown as ranges and means..., and further aid in the classification to predominant commodity group" (Copley et al. 2005.507). It was suggested that the environmental variations in $\delta^{13} \mathrm{C}$ values (calculated in $\Delta^{13} \mathrm{C}$ proxy) would potentially have the effect of shifting the $\delta^{13} \mathrm{C}$ values of the extracts along the axis of the ellipses. The mixing model postulates that within the percentage abundance of each fatty acid in reference porcine and ruminant fats and their $\delta^{13} \mathrm{C}$ values, "a contribution of porcine fat equal to or greater than 75 per cent of the total mixture were classed as "predominantly porcine" (Mukherjee et al. 2007.749).

In looking for milk and pig 'signatures' in prehistory the analysis of TAGs distributions in extracted lipids have recently been reactualized. TAGs are ma- jor constituents of animal fats, and their carbon number distributions in pottery lipids have been recognised as a biomarker of lipid origin to species level. The biomarker studies of modern animal fats have shown that bovine adipose fats contain saturated TAGs of total acyl carbon numbers that range between $\mathrm{C}_{42}$ and $\mathrm{C}_{54}$. Ovine adipose fats contain TAGs ranging from $\mathrm{C}_{44}$ to $\mathrm{C}_{54}$. In milk fat, the TAGs distribution is very broad, ranging from $\mathrm{C}_{28}$ to $\mathrm{C}_{54}$ due to presence. In body fat of non-ruminant species (porcine) the TAGs range from $\mathrm{C}_{44}$ to $\mathrm{C}_{54}$, with very low amounts of $\mathrm{C}_{44}, \mathrm{C}_{46}$ and $\mathrm{C}_{48}$ (Regert 2011.186) (Fig. 21).

The analyses of prehistoric pottery showed that about $19 \%$ of extracted lipid residues display preserved TAGs. The carbon number distributions of half of them, either indicative of degraded dairy or adipose fat, correlate well with $\delta 13 \mathrm{C}$ values of $\mathrm{C}_{16: 0}$ and $\mathrm{C}_{18: 0} \mathrm{FAs}$, and $\triangle{ }^{13 \mathrm{C}}$ proxy values of the same samples (Mukherje et al. 2008; Copley et al. 2005a; 20005b; 2005c) (Fig. 22). Biomolecular and isoto- 


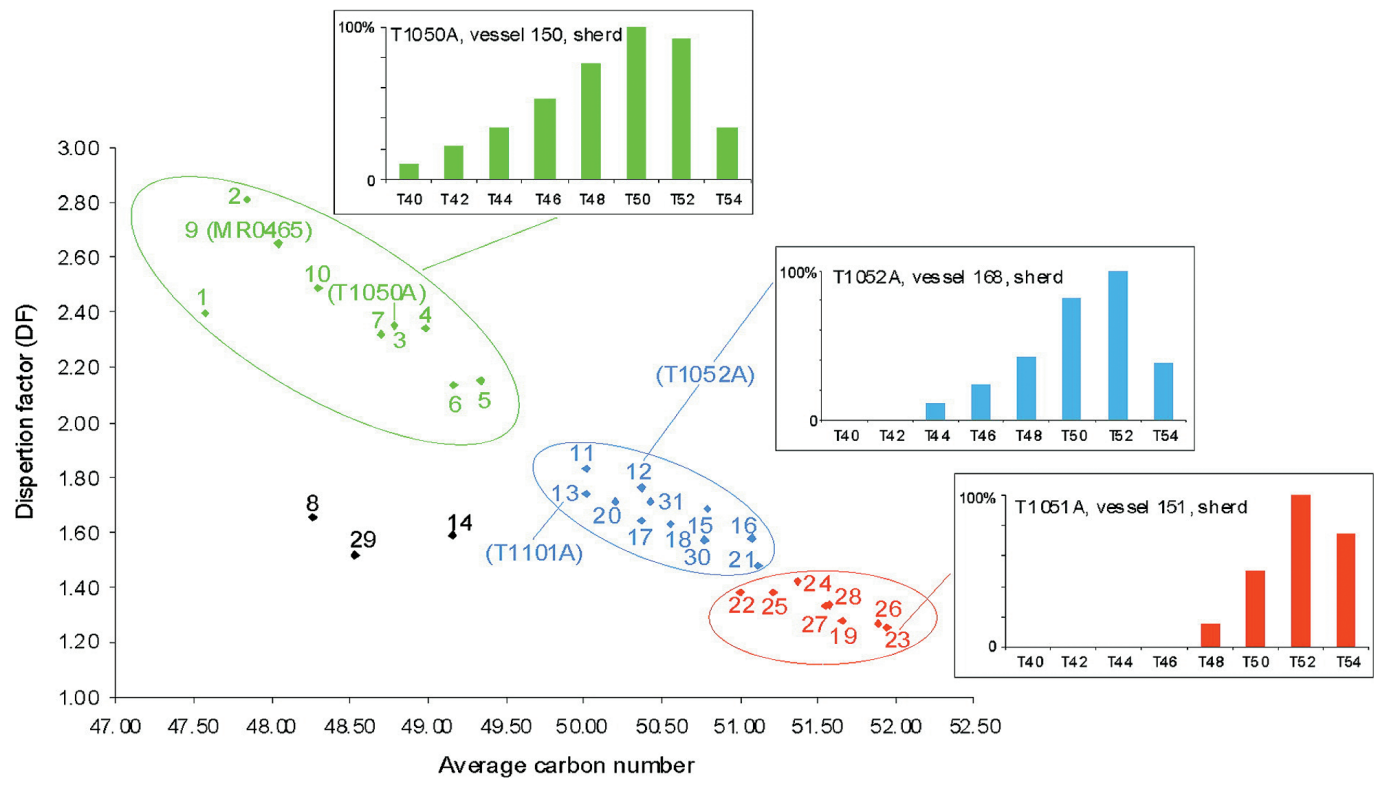

Fig. 23. Statistical 'reference confidence ellipses' model was calculated for TAGs distributions in modern reference and late Neolithic pottery extracts using average carbon number and dispersion factor (reprinted with permission from Mirabaud, Rolando and Regert 2007.Fig. 2, copyright 2007, American Chemical Society).

pic data have thus been equally used in detecting and interpreting the exploitation of domesticated animals for their 'secondary products', and their roles in non-domestic ceremonial contexts.

A parallel statistical 'reference confidence ellipses' model was calculated for TAGs distributions in modern reference and late Neolithic pottery extracts (Mirabaud, Rolando and Regert 2007). TAGs distributions of cow, sheep and goat milk were analysed after decay in the laboratory when absorbed into unglazed replica pottery. By calculating the 'average carbon numbers in the TAGs distribution' the three different 'classes' of TAGs distribution were determined; they are reminiscent of earlier calculated 'reference confidence ellipses' of three fat types. The 'first class' relates to a 'large distribution of TAGs, from $\mathrm{T}_{40}$ to $\mathrm{T}_{54}$ ', which can be associated with degraded dairy products. The second relates to the 'medium distribution of TAGs, from $\mathrm{T}_{44}$ to $\mathrm{T}_{54}$ ', and to body degraded fat. The third relates to a "narrow distribution of TAGs, from $\mathrm{T}_{46}$ or $\mathrm{T}_{48}$ to $\mathrm{T}_{54}$ ', which can be associated with body fats (Ibid. 6180) (Fig. 23).

However, it is "necessary to consider TAGs distributions as preliminary information" in detecting the origins of FAs (Regert 2011.188). Laboratory experiments showed that TAGs distributions are unstable when absorbed in a pottery matrix. They are degraded by hydrolysis and microbial activity during deposition. Degradation pathways are not fully understood yet, and might differ, depending on the burial micro environments. We already mentioned that when released from TAGs by hydrolysis, the shortand medium chain FAs are more water soluble than their long-chain counterparts. Over 90 days, the distribution of FAs in milk was transformed into a distribution similar that of the adipose fats. Research in food sciences has demonstrated that FAs decomposition is an extremely complex process that can produce a diverse range of organic compounds, depending on environment (Eerkens 2007).

The $\Delta^{13} \mathrm{C}$ correction factor was recognised, on the other hand, as a 'very powerful' tool to decouple the proxy from the $\mathrm{C}_{3} / \mathrm{C}_{4}$ and other environmental influences, which makes reference fat data sets (collected in the UK) with relating confidence ellipses and their $\Delta 13 \mathrm{C}$ values 'globally applicable' (Evershed 2009.417; Salque 2012). The $\Delta 13 \mathrm{C}$ proxy approach has recently been used to provide the earliest evidence for prehistoric milk use in Southeast Europe, Anatolia and the Levant (Evershed et al. $2008 a$ ). It was shown that milk was in use by the $7_{\text {th }}$ millennium $\mathrm{BC}$ and that milking was particularly important in north-west Anatolia, pointing to regional differences linked with conditions more favourable to cattle compared with other regions, where sheep and goat were relatively common and milk use less important (Fig. 24). This work involved the greatest number of analysed pottery samples so far, 2225 in all, from 23 archaeological sites in the Levant, Anatolia, and Southeast Europe, dating from 6500-3500 BC. Surprisingly, only 255 pottery sam- 

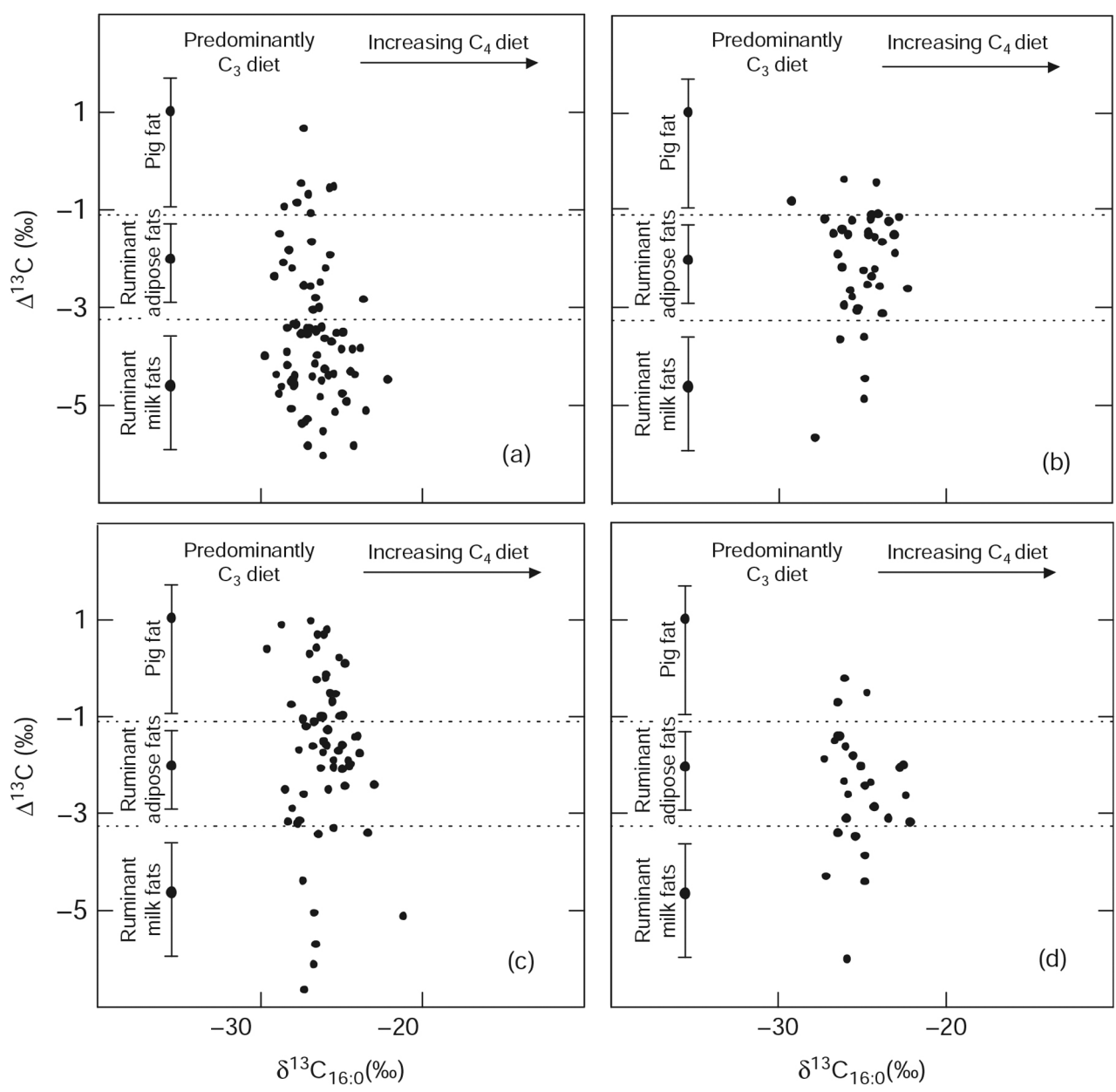

Fig. 24. Plots of the $\Delta 13 \mathrm{C}$ values for Early Neolithic animal fat residues in pottery show the milk use in Southeastern Europe and Anatolia dating back to the $7^{\text {th }}$ millennium BC. Pottery was from: (a) northwestern Anatolia; (b) central Anatolia; (c) northern Greece; and (d) eastern Anatolia and the Levant (reprinted by permission from Macmillan Publishers Ltd: Nature, Evershed et al. 2008a.Fig. 3, copyright 2008).

ples contained absorbed residues, a substantially smaller number than anticipated from past experience with pottery assemblages from UK. The relatively low success rate might have been due to increased diagenesis in warmer climates and variations in the calcareous soil conditions in Southeast Europe, Anatolia, and the Levant, or could possibly reflect differences in the absorptive powers of the types of clay used in different parts of the world. The results showed that milk was being used in all the regions from which potsherds were obtained, including the earliest sites, and that dairying was particularly widespread in northern Anatolia. In this area, $70 \%$ of the potsherds that contained residues yielded strong signs of the presence of milk. In contrast, at sites from eastern Turkey and the Levant, closer to the areas where farming began, the proportion of pottery showing signs of milk usage were much smaller. This distribution may relate to differences in the vegetation patterns of the various regions, with parts of northern Anatolia providing much better grazing conditions than eastern Turkey and the Levant, thus being more suitable for breeding cattle.

Recently, Michael Gregg and Greg Slater were able to extract $\mathrm{C}_{16: 0}$ and $\mathrm{C}_{18: 0}$ FAs from 34 of 65 archaeological pottery fragments $(52 \%)$ from nine Neolithic settlements in the Middle East dated between 7300 and 4700 calBC by using a microwave-assisted liquid chromatography solvent extraction protocol in combination with purification and analytical protocols. The isotopic values are consistent with those obtained from the modern body fats of wild boar and goat pastured on lands adjacent to the Jordan Valley, and residues from a modern pottery vessel used in the manufacture of yoghurt in Central Turkey (Gregg, Slater 2010.835).

The long sequence of dairying and milk usage was recently embedded within the archaeogenetic scenario of demic diffusion of Near Eastern farmers and 


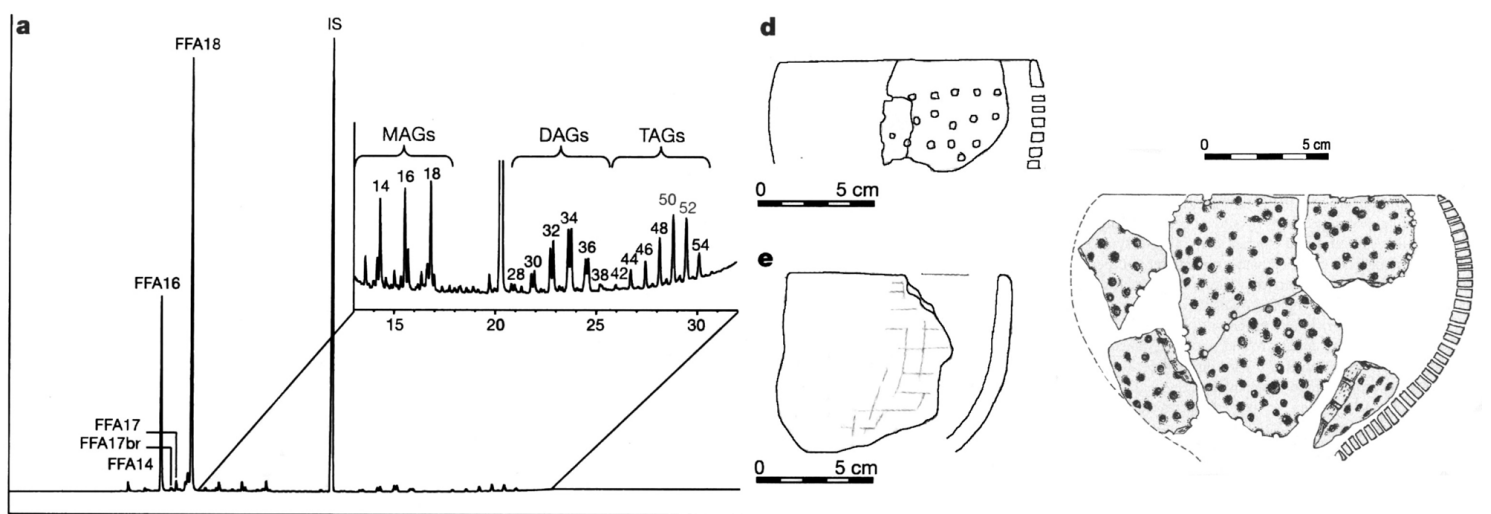

Fig. 25. Partial gas chromatograms of total lipid extracts from ceramic sieve associated with cheese production in Linear Pottery culture (reprinted by permission from Macmillan Publishers Ltd: Nature, Salque et al. 2012.Figs. 1-2, copyright 2012).

the evolution of lactase persistence in the Neolithic population in Eurasia. It was hypothesised on the one hand that strong selection for lactase persistence runs within the 'niche construction' at the forefront of the demic diffusion, where local environmental conditions and subsistence strategies led to a population increase and concentration on milk resources (Gerbault et al. 2011). On the other hand, it was suggested that lactase persistence appears in a relatively short period among dairy farmers in the northern Balkans in the Starčevo and Körös cultures, and is subsequently dispersed by demic diffusion to Central and Western Europe in the area of Linear Pottery (Itan et al. 2009). However, archaeogenetic analyses revealed an absence of the lactase gene in Neolithic populations in Europe, suggesting that lactase persistence was very low or even zero (Leonar$d i$ et al. 2012.93; for a discussion, see Budja et al. 2013).

The first farmers were probably lactose intolerant and could not have used unprocessed milk without

\begin{tabular}{|c|c|c|c|c|c|}
\hline & & Triacylglycerols & Fatty acids & Other constituents & $\delta^{13} \mathrm{C}$ and $\Delta^{13} \mathrm{C}$ signature \\
\hline 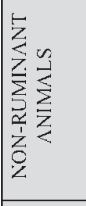 & $\begin{array}{l}\text { Porcine } \\
\text { adipose fats }\end{array}$ & $\begin{array}{l}\text { - Narrow distribution } \mathrm{C}_{44} \text { to } \mathrm{C}_{54} \text { with } \\
\text { low abundance of } \mathrm{C}_{44}, \mathrm{C}_{46} \text { and } \mathrm{C}_{54} \\
\text { - Rich in tripalmitin } \\
\text { - Palmitic acid prefercntially located in } \\
\text { the 2-position (P:S ratio in sn-2 } \\
\text { position is of } \approx 95: 5 \text { ) }\end{array}$ & $\begin{array}{l}\text { - } C_{1600} \text { more abundant than } C_{18: 0} \\
\text { - Absence of minor odd carbon number } \\
\text { fatty acids } \\
\text { - Monounsaturated fatty acid: only a } \\
\text { single isomer } Z \text {-9-octadecenoic acid }\end{array}$ & $\begin{array}{l}\text { - Odd-numbered ketones ranging } \\
\text { from } \mathrm{C}_{29} \text { to } \mathrm{C}_{35} \text {, maximising at } \mathrm{C}_{33} \\
\text { - Monounsaturated ketones with } 33 \\
\text { and } 35 \text { carbon atoms } \\
\text { Result from condensation of fatty } \\
\text { acids during heating animal fats } \\
\text { - Free or bound oxidised fatty acids } \\
\text { (diacids, hydroxy-acids), Fig. } 11\end{array}$ & $\begin{array}{l}\text { - Palmitic and stearic acids } \\
\text { enriched in }{ }^{13} \mathrm{C} \text { compared to } \\
\text { ruminant fats (Fig. 18) } \\
-\Delta^{13} \mathrm{C}>-1 \% \text { (Fig. } 21, \mathrm{D} \text { ) }\end{array}$ \\
\hline \multirow{3}{*}{ 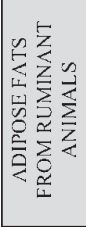 } & $\begin{array}{l}\text { Cattle } \\
\text { adipose fats }\end{array}$ & $\begin{array}{l}\text { - Distribution from } C_{42} \text { to } C_{54} \\
\text { - } P: S \text { ratio in } s n-2 \text { position is of } \approx 60: 40\end{array}$ & \multirow{3}{*}{$\begin{array}{l}\text { - } C_{16: 0} \text { less abundant than } C_{18: 0} \\
\text { - Low amount of straight carbon chain } \\
\text { with odd carbon number, specifically } C_{15: 0} \\
\text { and } C_{17: 0} \\
- \text { Low amount of branched-chain alkanoic } \\
\left.\text { acid ( } C_{15: 0} \text { and } C_{17: 0}\right) \\
\text { - Mixturc of isomers of octadecenoic acid } \\
\text { (double bond at } 9,11,13,14,15 \text { and } 16- \\
\text { positions) }\end{array}$} & \multirow{3}{*}{$\begin{array}{l}\text { - Same ketones as for porcine } \\
\text { adiposc fats }\end{array}$} & \multirow{3}{*}{$\begin{array}{l}-\Delta^{13} \mathrm{C} \text { from }-3 \text { to - } 1 \% \text { (Fig. } \\
21, \mathrm{D})\end{array}$} \\
\hline & $\begin{array}{l}\text { Goat adipose } \\
\text { fats }\end{array}$ & $\begin{array}{l}\text { - Distribution from } \mathrm{C}_{44}\left(\text { trace) to } \mathrm{C}_{54}\right. \\
\text { - P:S ratio in } s n-2 \text { position is of } \approx 60: 40\end{array}$ & & & \\
\hline & $\begin{array}{l}\text { Shecp } \\
\text { adipose fats }\end{array}$ & $\begin{array}{l}\text { - Distribution from } C_{44} \text { (trace) to } C_{54} \\
\text { - P:S ratio in } s n-2 \text { position is of } \approx 60: 40\end{array}$ & & & \\
\hline \multirow{3}{*}{ 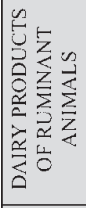 } & Cow milk & $\begin{array}{l}\text { - Large distribution from } \mathrm{C}_{40} \text { to } \mathrm{C}_{54} \\
\text { - in all triacylglyccrols, } \mathrm{C}_{1000} \text { present at } \\
\text { lower abundance than in goat milk }\end{array}$ & \multirow{3}{*}{$\begin{array}{l}\text { - Same fatty acids as for adipose fats of } \\
\text { ruminant animals }\end{array}$} & \multirow{3}{*}{$\begin{array}{l}\text { - Same ketones as for porcine } \\
\text { adipose fats }\end{array}$} & \multirow{3}{*}{$\begin{array}{l}-\mathrm{C}_{18: 0} \text { depleted in }{ }^{13} \mathrm{C} \text { in } \\
\text { comparison with adipose } \\
\text { animal fats } \\
-\Delta^{13} \mathrm{C}<3.3 \%\end{array}$} \\
\hline & Sheep milk & - Large distribution from $\mathrm{C}_{40}$ to $\mathrm{C}_{54}$ & & & \\
\hline & Goat milk & $\begin{array}{l}\text { - Large distribution from } \mathrm{C}_{40} \text { to } \mathrm{C}_{54} \\
\text { - in all triacylglycerols, } \mathrm{C}_{10: 0} \text { present at } \\
\text { higher abundance than in cow milk }\end{array}$ & & & \\
\hline \multirow{3}{*}{ 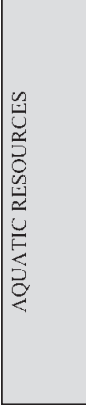 } & Marine fish & Not preserved & $\begin{array}{l}\text { - Palmitic acid more abundant than stearic } \\
\text { acid }\end{array}$ & \multirow[b]{2}{*}{$\begin{array}{l}\text { - Presence of isoprenoid acids } \\
\text { (phytanic acid } 3,7,11,15- \\
\text { tetramethylhexacosanoic acid and } \\
4,8,12 \text {-trimethyltridecanoic acid }= \\
4,8,12 \text {-TMDT) at low abundance } \\
\text { - Scries of isomers containing } 16, \\
18 \text { and } 20 \text { carbon atoms of } \omega-(0- \\
\text { alkylphenyl) alkanoic acids (cyclic } \\
\text { compounds) with a wide range of } \\
\text { positional isomers formed by } \\
\text { degradation of triunsaturated fatty } \\
\text { acids }\end{array}$} & \multirow{2}{*}{$\begin{array}{l}\text { - Palmitic and stearic acids ar } \\
\text { isotopically cnriched in }{ }^{13} \mathrm{C} \\
\text { compared to those of } \\
\text { terrestrial animals, } \\
\text { eventhough they plot not far } \\
\text { from adipose fats of domestic } \\
\text { pigs (Fig. 18) }\end{array}$} \\
\hline & & & $\begin{array}{l}\text { - Long chain fatty acids with more than } \\
18 \text { carbon atoms } \\
\text { - Triunsaturated fatty acids (usually not } \\
\text { preserved in archaeological contexts) }\end{array}$ & & \\
\hline & $\begin{array}{l}\text { Freshwater } \\
\text { fish }\end{array}$ & Not preserved & - Same acids as for marine fish & $\begin{array}{l}\text { - Same constituents as for marine } \\
\text { fish }\end{array}$ & $\begin{array}{l}\text { - freshwater fishes are } \\
\text { depleted in }{ }^{13} \mathrm{C} \text { for both } C_{16: 0} \\
\text { and } C_{18: 0} \text { fatty as compared to } \\
\text { marine resources }\end{array}$ \\
\hline
\end{tabular}

Fig. 26. Summary of molecular and isotopic criteria to distinguish animal fats in archeological ceramic vessels (reprinted from Regert 2011.Tab. 2, copyright 2010 by Wiley Periodicals, Inc.). 

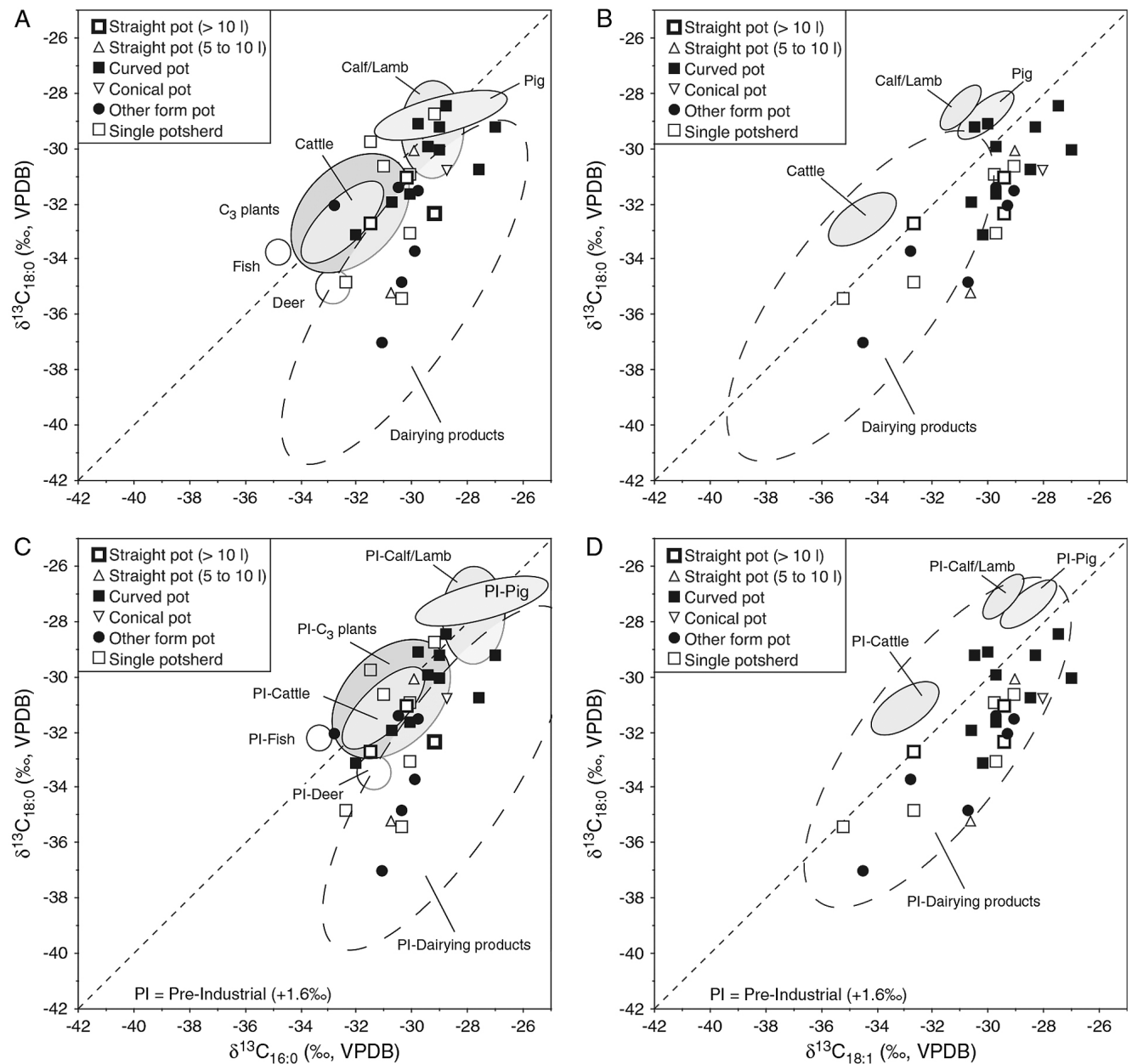

Fig. 27. Comparison of the carbon isotope composition of stearic acid ( $\left.\delta^{13} C_{18: 0}\right)$ versus palmitic $\left(\delta^{13} C_{16: 0}\right)$ and oleic $\left({ }^{13} C_{18: 1)}\right)$ acid of organic residues from Arbon Bleiche 3 Neolithic site with those of modern (A and $B$ ) and pre-industrial animal and plant fats (C and D) (reprinted from Spangenberg et al. 2006. Fig. 5, copyright 2005, with permission from Elsevier).

having digestive problems. It should be noted that lactose is progressively reduced by milk processing. The lactose content of fresh milk ranges between $4.42-5.15 \mathrm{~g} / \mathrm{g} \%$ in cattle, $4.66-4.82 \mathrm{~g} / \mathrm{g} \%$ in goats and $4.57-5.40 \mathrm{~g} / \mathrm{g} \%$ in sheep. It can be reduced to $50-$ $60 \%$ by bacterial fermentation. Some processed milk products (such as cheese and butter) have very low lactose content, ranging from 0-3.7g/g\% (Nagy 2011. 267). Lactose intolerant farmers were thus able to digest processed milk products better than fresh milk. It would therefore be possible that the earliest dairy farmers not only recognised the nutritive value of milk, but also understood how to convert milk into what would have been, for them, more palatable dairy products. Milk is extremely perishable and many methods have been developed to preserve it; fermentation was the earliest method. Inoculating fresh milk with the appropriate bacteria can ferment milk at temperatures that favour bacterial growth. As the bacteria grow, they convert milk sugar or lactose into lactic acid. The lowered $\mathrm{pH}$ caused by lactic acid preserves the milk by preventing the growth of pathogenic bacteria, which do not grow well in acidic conditions. The lactic acid bacteria (e.g., Lactobacillus acidophilus, Lactobacillus bulgaricus, Lactobacillus caucasius and Lactococcus lactis) thus turn milk into yoghurt, kefir, buttermilk and cheese. They make milk available as a nutritional source throughout the entire life of individuals, and also have advantages for storing and transporting dairy products and making them available in periods of low milk production on the other.

The presence of abundant milk fat in specialised vessels comparable in form to modern cheese strainers was identified in Northern Europe in the Early Neolithic LBK complex at $c .5200$ and $4900-4800$ calBC. It provides compelling evidence that vessels were used to separate fat-rich milk curds from the lactosecontaining whey, which is characteristic of the production of cheese (Salque et al. 2012) (Fig. 25). In Scandinavia, further to the north, dairy fat residue 

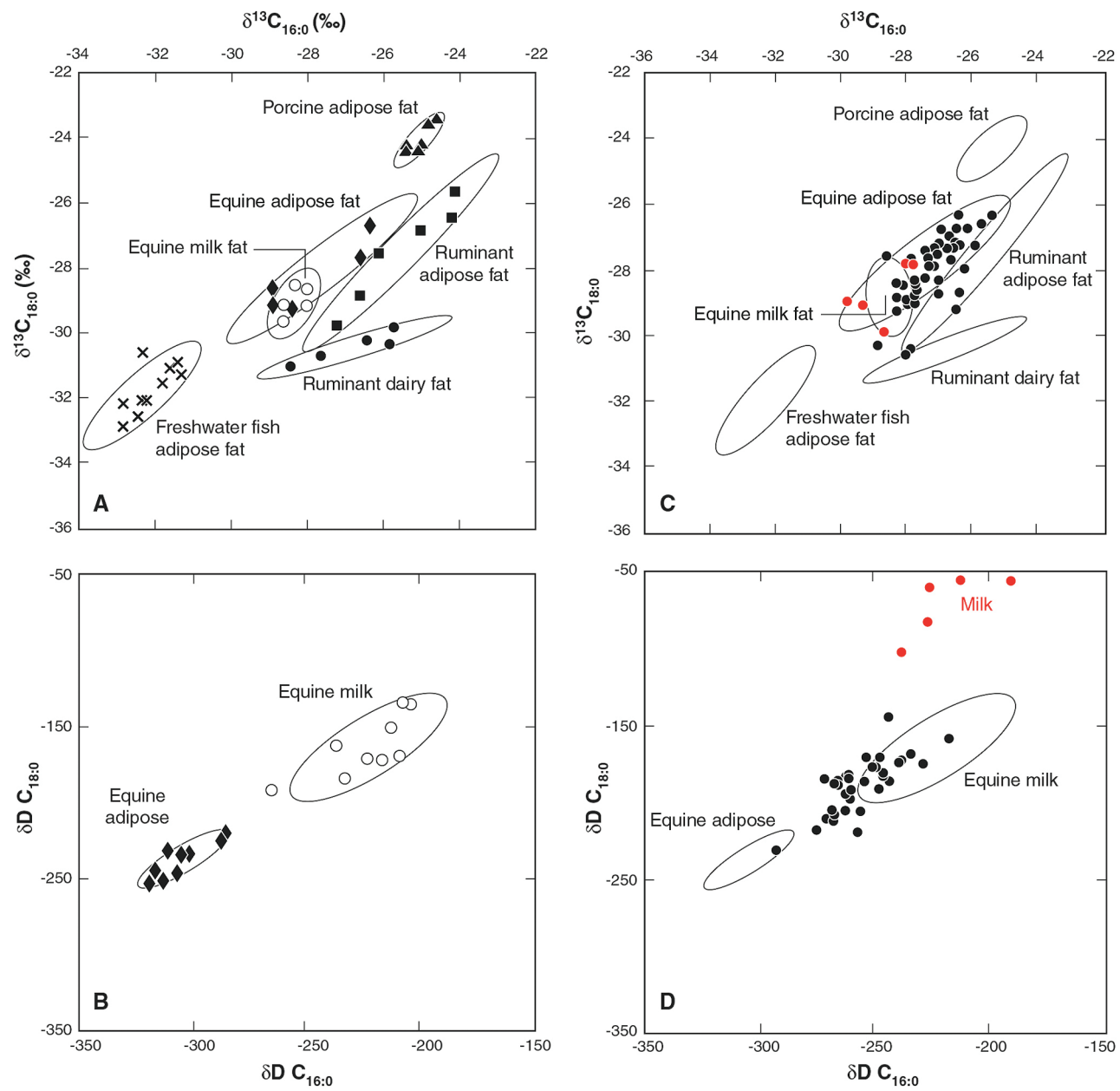

Fig. 28. Scatter plots of $\delta^{13} C$ and $\delta D$ values of the $C_{18: 0}$ and $C_{16: 0}$ fatty acid animal fats of modern reference fats ( $A$ and $B$ ) and of organic residues from archaeological pottery (C and D) from Kazakhstan. $C$ shows the $\delta^{13} C$ values of $C_{18: 0}$ and $C_{16: 0}$ FAs extracted from 89 pottery fragments of Eneolithic Botai culture; and (D) shows the $\delta D$ values of the $C_{18: 0}$ and $C_{16: 0}$ FAs of the residues from pottery assigned as equine fats. All confidence ellipses correspond to the values exhibited by modern reference fats. The residues highlighted in red correspond to archaeological equine milk fats (from 0utram et al. 2009.Fig. 3, reprinted with permission from AAAS).

was found in Corded Ware culture at c. $2500 \mathrm{calBC}$ (Cramp et al. 2014b). Oliver Craig et al. (2005) provided much earlier data for milk processing in the Early Neolithic in Southeast Europe. Degraded ruminant fatty acid in pottery in the Starčevo-Criş (59505500 calBC) and Köros cultures (5800-5700 calBC) suggest milk products and milk processing, i.e. the heating of milk. In the Northern Adriatic, initial milk processing is well embedded in Vlaška culture in the time span 5467-5227 calBC (Budja et al. 2013).

Towards a new perception of reference isotopic values of modern animal fats and $\Delta^{13} \mathrm{C}$ proxies

While all the molecular and isotopic criteria useful for discriminating different animal fats have been summarised (Regert 2011.Tab. 2) (Fig. 26), many recent studies of organic residues in archaeological pottery from Neolithic sites in Central Europe, Near
East and Central Asia have raised questions about the use of stable carbon isotope values obtained from modern reference fats from animals pastured in the UK to characterise ancient organic residues from other regions of the world.

Gregg and Slater (2010.847-849; see also Gregg et al. 2009) noted that the isotopic ratios of adipose fats of wild boar from Palestine, domesticated sheep from Israel and dairy food residues from Turkey do not correlate with ranges of $\delta^{13} \mathrm{C}$ values for pig fats, and ruminant adipose and dairy fats from the UK. While $\delta^{13} \mathrm{C}$ values of $\mathrm{C}_{16: 0}$ and $\mathrm{C}_{18: 0}$ from sheep adipose fats from the Near East are significantly more positive, plotting near the observed range of domesticated pigs from the UK, those from wild boar adipose are both significantly more negative. None of the $\delta^{13} \mathrm{C}$ values of pottery lipids extracts plot below the $\Delta^{13} \mathrm{C}=-3.3$ line, and thus would not be catego- 


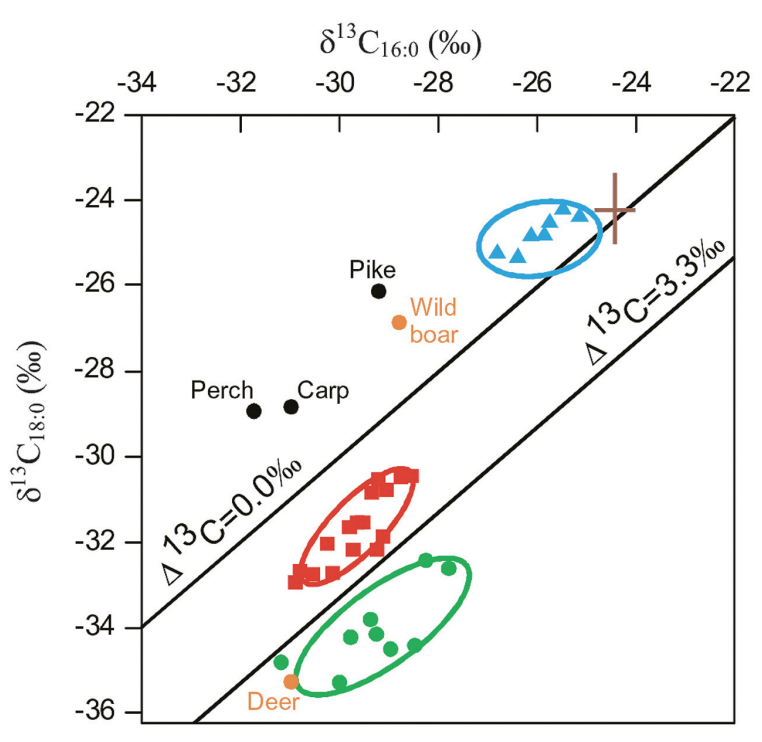

Fig. 29. Plot of the $\delta^{13} \mathrm{C}$ values obtained on reference wild and domestic animals. "Data in blue = porcine fats (Copley et al. 2003); in red = ruminant adipose fats (Copley et al. 2003); in green = ruminant milk fats (Copley et al. 2003). Data in orange = wild species (Craig et al. 2007b); brown crosses = marine fish (Craig et al. 2007b)" (reprinted from Regert 2011.200, Fig. 18, copyright 2010 by Wiley Periodicals, Inc.).

rised as dairy foods on the basis of the criteria postulated by Evershed et al., Copley et al., and Mukherjee et al. (see above). In Central Europe, $\delta^{13} \mathrm{C}$ values for ruminant adipose fats plot above the $\triangle 13 \mathrm{C}=$ 0 line, and within the range previously observed for pig fats.

Jorge E. Spangenberg et al.'s (2006) study of lipids extracts from Neolithic pottery and modern reference adipose and dairy fats from Central Europe has demonstrated that there is greater diversity in the fractionation of carbon isotopes associated with the synthesis of $\mathrm{C}_{16: 0}$ and $\mathrm{C}_{18: 0}$ FAs in ruminant and nonruminant animals than previously postulated. Stable carbon isotope values of modern pig fat, cow's milk, and goat cheese in this study all overlap the range of ruminant adipose values from the UK used to categorise potsherd extracts (Fig. 27). It was shown that the overlap in stable carbon isotope values of dairy foods and adipose fats of ruminant and nonruminant species can result from a wide range of other factors that affect fractionation, not only in the synthesis of FAs in the animals themselves, but also during the subsequent preparation and storage of fermented milk byproducts. The boiling effect on modern milk samples showed different changes in the $\delta 13 \mathrm{C}$ values for the main FAs $\mathrm{C}_{18: 0}$ and $\mathrm{C}_{18: 1}$ in cow, goat and sheep milk during heating. The differences in $\delta^{13} \mathrm{C}$ values were up to $8 \%$. On the other hand, these FAs in sheep and goat cheese samples are enriched in $13 \mathrm{C}$ by $\sim 4 \%$ o compared to raw milk samples. This isotopic shift probably reflects the bacterial degradation of long-chain FAs during cheese making and storage (Spangenberg et al. 2006.9-11; 2008.197-198). Interestingly, the $\delta^{13} \mathrm{C}$ values of $\mathrm{C}_{16: 0}$ and $\mathrm{C}_{18: 0}$ FAs from adipose fats from suckling calf and lamb cluster in the range of adult pig adipose. It was suggested that the use of glucose from mother's milk as carbon source for fatty acid biosynthesis by young animals probably explains why their adipose fat plots near porcine fats that derive from acetate and glucose carbon source, but not in the range of adult ruminant animals that mainly use acetate as a carbon source for fatty acid biosynthesis (Spangenberg et al. 2006.8-9).

On the Kazakh steppe in Central Asia, isotopic values for modern ruminant dairy fats have also been reported as plotting above the $\Delta 13 \mathrm{C}=-3.3$ line. The $\delta 13 \mathrm{C}$ values of horse milk and adipose fats fall within the range of previously published values for the adipose fats of ruminants in Northern Europe (Outram et al. 2009) (Fig. 28). However, $\delta^{13} \mathrm{C}$ values are not appropriate to discriminate mare's milk from horse carcass fats. Alan Outram et al. (2009.13341335) have introduced another proxy, the compound-specific deuterium isotope ( $\delta \mathrm{D})$ analysis, to discriminate milk and subcutaneous horse fats, and it was shown that the $\delta \mathrm{D}$ values obtained for these two types of horse products were distributed in two distinct clusters. The difference in values between milk and carcass fat is related to the variation $\mathrm{kn} \delta \mathrm{D}$ values of summer and winter precipitation that differ importantly (>100\%) on the Kazakh steppe. Adipose fats integrate water and dietary signal of all year, while mares produce milk only in summer to feed their foals, which explains the difference in $\delta \mathrm{D}$ signals between equine milk and adipose fats.

In the context of the hypothesised Mesolithic - Neolithic dietary shift in Northern Europe, $\delta 13 \mathrm{C}$ values for $\mathrm{C}_{16: 0}$ and $\mathrm{C}_{18: 0}$ FAs of a range of marine and freshwater (pike, perch, and carp) fish were determined. Marine fats have shown to be isotopically enriched in ${ }^{13} \mathrm{C}$ compared to those of terrestrial animals, even though they plot not far from adipose fats of domestic pigs (Craig et al. 2007) (Fig. 29). The available data show that freshwater fishes are depleted in ${ }^{13} \mathrm{C}$ for both $\mathrm{C}_{16: 0}$ and $\mathrm{C}_{18: 0}$ FAs as compared to marine fishes. It was suggested that the formation of $\omega$-(o-alkylphenyl) alkanoic acids 'could be undeniably considered as biodegradation markers of marine products' and evidence of fish consumption 
(Regert 2011.192; see also Evershed et al. 2008b; Cramp et al. 2014a; Cramp, Evershed 2014). Lucija Šoberl et al. (this volume) show they can occur in high frequencies together with long-chain n-alcohols of $\mathrm{C}_{22}$ to $\mathrm{C}_{32}$ even-carbon number series and analogous odd-carbon number n-alkane series of $\mathrm{C}_{23}$ to $\mathrm{C}_{33}$ chain length, which are more characteristic of degraded plant waxes.
There is no doubt, however, that since the 1990s the determination of the nature and origin of lipids, which mostly derived from degraded animal fats based on the distribution of FAs, sterols, MAGs, DAGs, and TAGs, was a great challenge because they reflect a range of complex transformations and mixtures and have undergone a series of alteration processes.

\section{References}

Brown T., Brown K. 2011. Biomolecular Archaeology An Introduction. Wiley-Blackwell. Chichester.

Braun D. 1983. Pots as Tools. In J. A. Moore, A. S. Keene (eds.), Archaeological Hammers and Theories. Academic Press. New York: 107-34.

Budja M., Ogrinc N., Žibrat Gašparič A., Potočnik D., Žigon D. and Mlekuž D. 2013. Transition to farming - transition to milk culture: Mala Triglavca case study. Documenta Praehistorica 40: 97-118.

Charters S., Evershed R. P., Goad L. J., Leyden A., Blinkhorn P. W. and Denham V. 1993. Quantification and distribution of lipid in archaeological ceramics: implications for sampling potsherds for organic residue analysis and the classification of vessel use. Archaeometry 35(2): 211223.

Charters S., Evershed R. P., Blinkhorn P. W. and Denham V. 1995. Evidence for the mixing of fats and waxes in archaeological ceramics. Archaeometry 37:113-127.

Charters S., Evershed R. P., Quye A., Blinkhorn P. W. and Reeves V. 1997. Simulation experiments for determining the use of ancient pottery vessels: the behaviour of epicuticular leaf wax during boiling of a leafy vegetable. Journal of Archaeological Science 24: 1-7.

Colombini M. P., Modugno F. 2009. Organic Mass Spectrometry in Art and Archaeology. Wiley. Chichester.

Copley M. S., Rose P. J., Clapham A., Edwards D. N., Horton M. C. and Evershed R. P. 2001. Detection of palm fruit lipids in archaeological pottery from Qasr Ibrim, Egyptian Nubia. Proceedings of the Royal Society of London. Series $B$ 268: 593-597.

Copley M. S., Berstan R., Dudd S. N., Docherty G., Mukherjee A , Straker V., Payne S. and Evershed R. P. 2003. Direct chemical evidence for widespread dairying in prehistoric Britain. Proceedings of the National Academy of Sciences USA 100: 1524-1529.
Copley M. S., Berstan R., Dudd S. N., Aillaud S., Mukherjee A. J., Straker V. and Evershed R. P. 2005. Processing of milk products in pottery vessels through British prehistory. Antiquity 79(306): 895-908.

Copley M. S., Berstan R., Dudd S. N., Straker V., Payne S. and Evershed R. P. 2005a. Dairying in antiquity. I. Evidence from absorbed lipid residues dating to the British Iron Age. Journal of Archaeological Science 32: 485-503.

Copley M. S., Berstan R., Straker V., Payne S. and Evershed R. P.2005b. Dairying in antiquity. II. Evidence from absorbed lipid residues dating to the British Bronze Age. Journal of Archaeological Science 32: 505-521.

Copley M. S., Berstan R., Mukherjee A. J., Dudd S. N., Straker V., Payne S. and Evershed R. P. 2005c. Dairying in antiquity. III. Evidence from absorbed lipid residues dating to the British Neolithic. Journal of Archaeological Science 32: 523-546.

Craig O. E., Collins M. J. 2002. The Removal of Protein from Mineral Surfaces: Implications for Residue Analysis of Archaeological Materials. Journal of Archaeological Science 29(10): 1077-1082.

Craig O. E., Chapman J., Heron C., Willis L. H., Bartosiewicz L., Taylor G., Whittle A. and Collins M. 2005. Did the first farmers of central and eastern Europe produce dairy foods? Antiquity 79(306): 882-894.

Craig 0. E., Forster M., Andersen H., Koch E., Crombé P., Milner N. J., Stern B., Bailey G. N. and Heron C. P. 2007. Molecular and isotopic demonstration of the processing of aquatic products in northern European prehistoric pottery. Archaeometry 49: 135-152.

Craig 0. E., Saul H., Lucquin A., Nishida Y., Taché K., Clarke L., Thompson A., Altoft D. T., Uchiyama J., Ajimoto M., Gibbs K., Isaksson S., Heron C. P. and Jordan P. 2013. Earliest evidence for the use of pottery. Nature 496: 351354. 
Cramp L. J. E., Jones J., Sheridan A., Smyth J., Whelton H., Mulville J., Sharples N. and Evershed R. P. 2014a. Immediate replacement of fishing with dairying by the earliest farmers of the northeast Atlantic archipelagos. Proceedings of the Royal Society of London. Series B 281: 20132372281.

Cramp L. J. E., Evershed R. P., Lavento M., Halinen P., Mannermaa K., Oinonen M., Kettunen J., Perola M., Onkamo P. and Heyd V. 2014b. Neolithic dairy farming at the extreme of agriculture in northern Europe. Proceedings of the Royal Society of London. Series B 281: 20140819.

Cramp L. J. E., Evershed R. P. 2014. Reconstructing Aquatic Resource Exploitation in Human Prehistory using Lipid Biomarkers and Stable Isotopes. In H. D. Holland, K. K. Turekian (eds.), Treatise on Geochemistry: Archaeology and Anthropology. Vol. 14. Elsevier. Oxford: 319339.

DeNiro M. J. 1987. Stable isotopy and archaeology. American Scientist 75(2): 182-191.

DeNiro M. J., Epstein S. 1978. Influence of diet on the distribution of carbon isotopes in animals. Geochimica et Cosmochimica Acta 42: 495-506.

Dudd S. N., Evershed R. P. 1998. Direct demonstration of milk as an element of archaeological economies. Science 282: $1478-1481$.

Dudd S. N., Regert M. and Evershed R. P. 1998. Assessing microbial contributions to absorbed acyl lipids during laboratory degradations of fats and oils and pure TAGs absorbed into ceramic potsherds. Organic Geochemistry 29 (5-7): $1345-1354$.

Dudd S. N., Evershed R. P. 1999. Evidence for varying patterns of exploitation of animal products in different prehistoric pottery traditions based on lipids preserved in surface and absorbed residues. Journal of Archaeological Science 26: 1473-82.

Eerkens J. W. 2007. Organic residue analysis and the decomposition of fatty acids in ancient potsherds. In H. Barnard, J. W. Eerkens (eds.), Theory and Practice in Archaeological Residue Analysis. British Archaeological Reports IS 1650. Archaeopress. 0xford: 90-98.

Evershed R. P. 1993. Biomolecular archaeology and lipids. World Archaeology 25(1): 74-93.

2008a. Experimental approaches to the interpretation of absorbed organic residues in archaeological ceramics. World Archaeology 40(1): 26-47. 2008b. Organic residue analysis in archaeology: the archaeological biomarker revolution. Archaeometry 50 (6): 895-924.

2009. Compound-specific Stable Isotopes in Organic Residue Analysis in Archaeology. In M. P. Colombini, F. Modugno (eds.), Organic Mass Spectrometry in Art and Archaeology. Wiley. Chichester: 391-430.

Evershed R. P., Heron C. and Goad L. J. 1990. Analysis of organic residues of archaeological origin by high-temperature gas chromatography/mass spectrometry. Analyst 115(10): 1339-1342.

1991. Epicutilar wax components in potsherds as chemical indicators of leafy vegetables in ancient diets. Antiquity 65(248): 540-544.

Evershed R. P., Heron C., Charters S. and Goad L. J. 1992. Chemical analysis of organic residues in ancient pottery: methodological guidelines and applications. In R. White, H. Page (eds.), Organic Residues in Archaeology: Their Identification and Analysis. United Kingdom Institute for Conservation of Historic and Artistic Works. Archaeology Section. London: 11-25.

Evershed R. P., Arnot K. L., Collister J., Eglinton G. and Chartes S. 1994. Application of isotope ratio monitoring gas chromatographymass spectrometry to the analysis of organic residues of archeological origin. Analyst 119: 909-914.

Evershed R. P, Charters S. and Quye A. 1995. Interpreting lipid residues in archaeological ceramics: Preliminary results from laboratory simulations of vessel use and burial. Materials Research Society Symposium Proceedings 352: 85-95.

Evershed R. P., Vaughan S. J., Dudd S. N. and Soles J. S. 1997 a. Fuel for thought? Beeswax in lamps and conical cups from late Minoan Crete. Antiquity 71(274): 979-985.

Evershed R. P., Mottram H. R., Dudd S. N., Charters S., Stott A. W., Lawrence G. J., Gibson A. M., Conner A., Blinkhorn P. W. and Reeves V. 1997b. New Criteria for the identification of animal fats in archaeological pottery. Naturwissenschaften 84: 402-406.

Evershed R. P., Dudd S. N., Charters S., Mottram H., Stott A. W., Raven A., van Bergen P. F. and Bland H. A. 1999. Lipids as carriers of anthropogenic signals from prehistory. Philosophical Transactions of the Royal Society of London. Series B 354: 19-31.

Evershed R. P., Dudd S. N., Copley M. S., Berstan R., Stott A. W., Mottram H., Buckley S. A. and Crossman Z. 2002. 
Chemistry of Archaeological Animal Fats. Accounts of Chemical Research 35: 660-668.

Evershed R. P. and 21 authors. 2008a. Earliest date for milk use in the Near East and southeastern Europe linked to cattle herding. Nature 455(7212): 528-531.

Evershed R. P, Copley M. S., Dickson L. and Hansel F. A. 2008b. Experimental evidence for the processing of marine animal products and other commodities containing polyunsaturated fatty acids in pottery vessels. Archaeometry 50(1): 101-113.

Gerbault P., Liebert A., Itan Y., Powell A., Currat M., Burger J., Swallow D. M. and Thomas M. G. 2011. Evolution of lactase persistence: an example of human niche construction. Philosophical Transactions of Royal Society. Series B 366: 863-877.

Gregg M. W., Banning E. B., Gibbs K. and Slater G. F. 2009. Subsistence practices and pottery use in Neolithic Jordan: molecular and isotopic evidence. Journal of Archaeological Science 36: 937-946.

Gregg A., Slater G. F. 2010. New method for extraction, isolation and transesterification of free fatty acids from archaeological pottery. Archaeometry 52(5): 833-854.

Hart J. P., Lovis W. A., Schulenberg J. K. and Urquhart G. R. 2007. Paleodietary implications from stable carbon isotope analysis of experimental cooking residues. Journal of Archaeological Science 34: 804-813.

Hart J. P., Urquhart G. R., Feranec R. S. and Lovis W. A. 2009 . Non-linear relationship between bulk $\delta^{13} \mathrm{C}$ and percent maize in carbonized cooking residues and the potential of false-negatives in detecting maize. Journal of Archaeological Science 36(10): 2206-2212.

Hart J. P., Lovis W. A., Jeske R. J. and Richards J. D. 2012. The potential of bulk $\delta^{13} \mathrm{C}$ on encrusted cooking residues as independent evidence for regional maize histories. American Antiquity 77(2): 315-325.

Hastorf C. A., DeNiro M. J. 1985. Reconstruction of Prehistoric Plant Production and Cooking Practices by a New Isotope Method. Nature 315: 489-491.

Henrickson E. F. 1990. Investigating Ancient Ceramic Form and Use: Progress Report and Case Study. In W. D. Kingery (ed.), The Changing Roles of Ceramics in Society: 26,000 B. P to the Present. Ceramics and Civilization. Vol. 5. American Ceramic Society. Westerville, Ohio: 83-117.

Henrickson E. F., McDonald M. M. A. 1983. Ceramic Form and Function: An Ethnographic Search and an Archaeological Application. American Anthropologist 85(3): 30-43.
Heron C., Evershed R. P. 1993. The Analysis of Organic Residues and the Study of Pottery Use. Archaeological Method and Theory 5: 247-284.

Itan Y., Powell A., Beaumont M. A., Burger J., Thomas M. G. 2009. The Origins of Lactase Persistence in Europe. PLoS Computational Biology 5(8): e1000491.

Kimpe K., Drybooms C., Schrevens E., Jacobs P. A., Degeest R. and Waelkens M. 2004. Assessing the relationship between form and use of different kinds of pottery from the archaeological site Sagalassos (southwest Turkey) with lipid analysis. Journal of Archaeological Science 31(11): 1503-1510.

Leonardi M., Gerbault P., Thomas M. G. and Burger J. 2012. The evolution of lactase persistence in Europe. A synthesis of archaeological and genetic evidence. International Dairy Journal 22: 88-97.

Mirabaud S., Rolando C. and Regert M. 2007. Molecular criteria for discriminating adipose fat and milk from different species by nanoESIMS and MS/MS of their TAGs: Application to archaeological remains. Analytical Chemistry 79: 6182-6192.

Mottram H. R., Dudd S. N., Lawrence G. J., Stott A. W. and Evershed R. P. 1999. New chromatographic, mass spectrometric and stable isotope approaches to the classification of degraded animal fats preserved in archaeological pottery. Journal of Chromatography A 833: 209-221.

Morton J. D., Schwarcz H. P. 2004. Paleodietary Implications from Stable Isotopic Analysis of Residues on Prehistoric Ontario Ceramics. Journal of Archaeological Science 31: 503-517.

Mukherjee A. J., Berstan R., Copley M. S., Gibson A. M. and Evershed R. P. 2007. Compound-specific stable carbon isotopic detection of pig product processing in British Late Neolithic pottery. Antiquity 81(313): 743-754.

Mukherjee A. J., Gibson A. M. and Evershed R. P. 2008. Trends in pig product processing at British Neolithic Grooved Ware sites traced through organic residues in potsherds. Journal of Archaeological Science 35: 20592073.

Nagy D., Tömöry G., Csányi B., Bogácsi-Szabó E., Czibula A., Priskin K., Bede 0., Bartosiewicz L., Stephen Downes C. and Raskó I. 2011. Comparison of Lactase Persistence Polymorphism in Ancient and Present-Day Hungarian Populations. American Journal of Physical Anthropology 145: 262-269.

Ogrinc N., Gams Petričić M., Žigon D., Žibrat Gašparič A. and Budja M. 2012. Pots and lipids: molecular and iso- 
tope evidence of food processing at Maharski prekop. Documenta Praehistorica 39: 339-347.

Ogrinc et al. 2015 in prep.

Oudemans T. F. M., Boon J. J. 1993. Traces of Ancient Vessel Use: Investigating Prehistorie Usage of four Pot Types by Organic Residue Analysis using Pyrolysis Mass Spectrometry. Analecta Praehistorica Leidensia 26: 221-234.

Oudemans T. F. M., Boon J. J. 2007. A comparative study of extractable lipids in the shards and surface residual crusts of ceramic vessels from Neolithic and Roman Iron Age settlements in the Netherlands. In H. Barnard, J. Eerkens (eds.), Theory and Practice of Archaeological Residue Analysis. British Archaeological Reports IS 1650. Archaeopress. 0xford: 99-124.

Oudemans T. F. M., Kubiak-Martens L. 2012. Botanical and chemical characterisation of charred organic residues in ceramics. In B. I. Smit, O. Brinkkemper, J. P. Kleijne, R. C. G. M. Lauwerier and E. M. Theunissen (eds.), Late Neolithic Behavioural Variability in a Dynamic Landscape: a Kaleidoscope of Gathering at Keinsmerbrug (the Netherlands). Cultural Heritage Agency of the Netherlands. Nederlandse Archeologische Rapporten 043. Amersfoort: 107-235.

Outram A. K., Stear N. A., Bendrey R., Olsen S., Kasparov A., Zaibert V., Thorpe N. and Evershed R. P. 2009. The Earliest Horse Harnessing and Milking. Science 323: 13321335.

Peters K. E., Walters C. C. and Moldowan J. M. 2005. The Biomarker Guide I. Biomarkers and Isotopes in the Environment and Human History. Cambridge University Press. Cambridge.

Pollard A. M., Batt C. M., Stern B. and Young S. M. M. 2007. Analytical Chemistry in Archaeology. Cambridge University Press. Cambridge.

Raemaekers D. C. M., Kubiak-Martens L. and Oudemans T. F. M. 2013. New food in old pots - charred organic residues in Early Neolithic ceramic vessels from Swifterbant, the Netherlands (4300-4000 calBC). Archäologisches Korrespondenzblatt 43(3): 315-334.

Raven A. M., van Bergen P. F., Stott A. W., Dudd S. N. and Evershed R. P. 1997. Formation of long-chain ketones in archaeological pottery vessels by pyrolysis of acyl lipids. Journal of Analytical and Applied Pyrolysis 40-41: 267285.

Reber E. A., Evershed R. 2004. Identification of maize in absorbed organic residues: a cautionary tale. Journal of Archaeological Science 31: 399-140.
Regert M., Bland H. A., Dudd S. N., Van Bergen P. F. and Evershed R. P. 1998. Free and bound fatty acid oxidation products in archaeological ceramic vessels. Proceedings of the Royal Society of London. Series B 265: 2027-2032.

Regert M. 2011. Analytical strategies for discriminating archeological fatty substances from animal origin. Mass Spectrometry Reviews 30: 177-220.

Rice P. 1987. Pottery Analysis: A Sourcebook. University of Chicago Press. Chicago.

Salque M. 2012. Was Milk Processed in these Ceramic Pots? In F. Feulner, P. Gerbault, R. Gillis, H. Hollund, R. Howcroft, M. Leonardi, A. Liebert, M. Raghavan, M. Salque, O. Sverrisdóttir, M. Teasdale, N. van Doorn and C. Wright (eds.), May Contain Traces of Milk. Investigating the role of dairy farming and milk consumption in the European Neolithic. Lactose Persistence and Early Cultural History of Europe. LeCHE. The Univesity of York. Heslington: 127-142.

Salque M., Bogucki P. I., Pyzel J., Sobkowiak-Tabaka I., Grygiel R., Szmyt M. and Evershed R. P. 2013. Earliest evidence for cheese making in the sixth millennium $\mathrm{BC}$ in northern Europe. Nature 493(7433): 522-525.

Schiffer M., Skibo J. 1987. Theory and Experiment in the Study of Technological Change. Current Anthropology 28 (5): 595-622.

Skibo J. M. 2013. Understanding Pottery Function. Manuals in Archaeological Method, Theory and Technique. Springer. New York.

Spangenberg J. E., Jacomet J. and Schibler J. 2006. Chemical analyses of organic residues in archaeological pottery from Arbon Bleiche 3, Switzerland - evidence for dairying in the late Neolithic. Journal of Archaeological Science 33(1): 1-13.

Spangenberg J. E., Matuschik I., Jacomet S. and Schibler J. 2008. Direct evidence for the existence of dairying farms in prehistoric Central Europe (4th millennium BC). Isotopes in Environmental and Health Studies 44(2): 189200.

Stacey R. J. 2009. Organic residues: origins, analysis and scope - an overview for the archaeological ceramicist. The old potter's almanack 14(1): 1-8.

Stott A. W., Davies E., Evershed R. P. and Tuross N. 1997. Monitoring the routing of dietary and biosynthesized lipids through compound specific stable isotope $\left(\delta^{13} \mathrm{C}\right)$ measurements at natural abundance. Naturwissenschaften 84: $82-86$ 
Šoberl L., Sraka M., Horvat M., Žibrat Gašparič A., Evershed R. and Budja M. 2014. Neolithic and Eneolithic activities as inferred from organic residue analysis of pottery from Mala Triglavca, Moverna vas and Ajdovska jama, Slovenia. Documenta Praehistorica 41: 149-180.

Vogel J. C. 1993. Variability of carbon isotope fractionation during Photosynthesis. In J. R. Ehleringer, A. E. Hall, and G. D. Farquhar (eds.), Stable Isotopes and Plant Water-Relations. Academic Press San Diego: 29-46.

Warinner C., Tuross N. 2009. Alkaline cooking and stable isotope diet-tissue discrimination in swine: archaeological implications. Journal of Archaeological Science 36: 1690-1697. 